\title{
Mycoflore de quelques variétés du fraisier (Fragaria ananassa L.), cultivées dans la région du Gharb et le Loukkos (Maroc)
}

Najoua MOUDEN, Rachid BENKIRANE, Amina OUAZZANI TOUHAMI et Allal DOUIRA

Laboratoire de Botanique, Biotechnologies et de Protection des Plantes, UFR de Mycologie, Département de

Biologie, Faculté des Sciences, BP. 133, Université Ibn Tofail, Kénitra, Maroc.

Corresponding author email: douirallal@hotmail.com;

Original submitted in on $8^{\text {th }}$ October 2012. Published online at www.m.elewa.org on 31st January 2013.

\section{RÉSUMÉ}

Objectif : Le principal but de cette étude a été la mise en évidence de la mycoflore associée aux plants de fraisier provenant de la principale région productrice dont certaines espèces fongiques peuvent provoquer des dégâts importants sur cette culture. Au Maroc, la culture de la fraise est localisée dans la région du Gharb et le Loukkos (nord-ouest), la superficie cultivée en 2010 a été de 3.035 ha avec une production de $140.600 \mathrm{~T}$.

Méthodologie et résultats : Des prospections réalisées en 2010 dans deux fraiseraies de la localité de Moulay Bousselham ont permis de montrer l'existence de nombreux symptômes (pourriture grise, Anthracnose) sur les plants de trois variétés de fraisier (Camarossa, Festival et Splander). Les isolements à partir des différents organes ont révélé la présence de 17 espèces fongiques à des fréquences variables. La fréquence d'isolement exprimée par le pourcentage de contamination et/ou d'infection de Botrytis cinerea a atteint $58,1 \%$ sur les fraises, $41,5 \%$ sur les tiges et $25,3 \%$ sur les feuilles respectivement des variétés Festival, Splander et Camarosa. Ce champignon a été également isolé des sclérotes, les pourcentages de contamination les plus importants sont rencontrés sur les feuilles $(39,8 \%)$ et les tiges $(48,19 \%)$. Sur Camarosa, il a été accompagné de Chaetomium globosum aux pourcentages de contamination de $32,8 \%$ et $28,3 \%$. Alternaria alternata a été rencontré sur les parties aériennes des plants de fraisier surtout sur les feuilles de Camarosa (42,03\%). Mucor sp. a été isolé des fraises de Camarosa à un pourcentage de contamination de 31,2\% accompagné de Fusarium avenaceum, Verticillium dahliae et Colletotrichum acutatum à des pourcentages ne dépassant pas $11,1 \%$. C. acutatum est isolé également des feuilles aux pourcentages de contamination de 27,73 et 23,7\% respectivement de Festival et Splander. Aspergillus nidulans, Ulocladium atrum, Stemphyllium botryosum, Fusarium semitectum et Gliocladium roseum sont retrouvés seulement sur les feuilles du fraisier aux pourcentages de 23,6\%,22,16\%,21,9\%, $11,3 \%$ et $11,06 \%$. Thielavia terricola, rencontré sur les feuilles à une fréquence de $32,8 \%$, est retrouvé aussi au niveau de la tige $(12,4 \%)$ et du collet $(20,8 \%)$. Stachybotrys atra est rencontré seulement sur la tige et les racines de Camarosa à des pourcentages faibles de $9,8 \%$ et $14,3 \%$. La présence de Fusarium oxysporum est marquée au niveau du collet $(44,8 \%)$ et des racines $(40,3 \%)$ par rapport aux feuilles. Fusarium solani est isolé du collet et racines de Festival aux pourcentages de 35,5 et $19,1 \%$, il est accompagné au niveau du collet par Rhizoctonia solani 33,3\%. Ce dernier champignon est également retrouvé au niveau du collet et des racines de Camarosa aux pourcentages de $23 \%$ et $28,4 \%$. 
Conclusion et application de résultats : Les plants de fraisier examinés hébergent un complexe fongique assez diversifié rassemblant des champignons pathogènes, antagonistes ou saprophytes et montrant des indications à propos de l'état sanitaire des plantes cultivées dans cette région et les maladies susceptibles d'y émerger.

Mots clés : Fraisier, symptômes, Mycoflore, Maroc.

\section{ABSTRACT}

Objective: The main purpose of this study was the identification of mycoflora associated with strawberry plants from the main producing area, located in the Gharb region and the Loukkos (northwest). In 2010, the cultivated area was 3,035 ha with a production of 140,600 Tonnes.

Methodology and results: Surveys carried out in 2010 in two strawberry farms in Moulay Bousselham showed the existence of numerous symptoms (gray mold, anthracnose) on the strawberry plants of three varieties (Camarossa, Festival and Splander). Isolation from different organs revealed the presence of 17 fungal species at varying frequencies. The isolation frequency expressed by the percentage of contamination and/or infection of Botrytis cinerea reached $58.1 \%$ on fruits, $41.5 \%$ in the stems and $25.3 \%$ on the leaves respectively in the varieties Festival, Splander and Camarosa. This fungus has also been isolated from sclerotia, but the most important percentages of contamination were encountered on the leaves (39.8\%) and stems (48.19\%). On the variety Camarosa, it was accompanied by Chaetomium globosum with the percentages of contamination of $32.8 \%$ and $28.3 \%$. Alternaria alternata was encountered on the aerial parts of strawberry plants especially on the leaves of Camarosa (42.03\%). Mucor $\mathrm{sp}$. was isolated from Camarosa strawberries with the percentage of contamination of $31.2 \%$ with Fusarium avenaceum, Verticillium dahliae and Colletotrichum acutatum with the percentages not exceeding $11.1 \%$. C. acutatum was also isolated from the leaves of Splander and Festival with the percentages of 27.73 and $23.7 \%$ respectively. Aspergillus nidulans, Ulocladium atrum, Stemphyllium botryosum, Fusarium semitectum and Gliocladium roseum were found only on the leaves of strawberry with the percentages of $23.6 \%, 22.16 \%, 21.9 \%, 11.3 \%$ and $11.06 \%$. Thielavia terricola, was found on leaves at a percentage of $32.8 \%$, was found also in the stem $(12.4 \%)$ and in the collar $(20.8 \%)$. Stachybotrys atra was found only in the stem and in the roots of Camarosa with low percentages of $9.8 \%$ and $14.3 \%$. The presence of Fusarium oxysporum was marked in the crown $(44.8 \%)$ and in the roots $(40.3 \%)$ relative to the leaves. Fusarium solani was isolated from the crown and from the roots of the Festival variety at percentages of 35.5 and $19.1 \%$, is accompanied at the neck by Rhizoctonia solani $33.3 \%$. This fungus was also found at the crown and roots of Camarosa with the percentages of $23 \%$ and $28.4 \%$.

Conclusion and Application of results: The Strawberry plants examined harbored a diverse pathogenic fungi, antagonist and saprophyte which can give indication about the health of the plants growing in this region and diseases likely to emerge.

Key words: Strawberry, symptoms, mycoflora, Morocco

\section{INTRODUCTION}

La culture du fraisier est l'une des cultures horticoles les plus répandues dans le monde. Au Maroc, la production de la fraise est localisée dans la région du Gharb et le Loukkos (Nord ouest). En 2010, la production de la Fraise a été de 140600 $\mathrm{T}$ pour une superficie de 3035 ha (Anonyme, 2012). Le Maroc a détenu une part de marché de $2 \%$ dans les exportations mondiales en 2009 et il a été classé 11 ème exportateur de la fraise; il exporte principalement vers la France, I'Espagne, Allemagne et le Royaume Uni (Anonyme, 2010). En 2009, les exportations ont été de 21602 tonnes (Anonyme, 2012). Les variétés de fraises les plus cultivées au Maroc sont d'origine californienne (Atta et Ezzat, 1999) avec une nette prédominance, ces dernières années, des variétés 
OsoGrande, Camarosa et Chandler. Deux types de plants sont utilisés par les agriculteurs, à savoir les plants en motte et les plants à racines nues qui restent les plus abondants. Par ailleurs, tous les agriculteurs utilisent des plants frais (Bamouh et al., 2012). Le fraisier est sujet à plusieurs contraintes phytosanitaires, les conditions climatiques et l'insuffisance des techniques de stockage favorisent l'apparition de plusieurs pathogènes responsables de la dépréciation des fraises. II peut être attaqué par les virus (Martin et al., 2004; Li and Yang, 2011), les bactéries (Mdarhri, 2005; Anonyme, 2006; Bull et al., 2009), les Acariens ( Zahdali 2003; Lagziri et El Amrani, 2009), les nématodes (Lamindia, 2002), les ravageurs (Nicolov, 2006), les mauvaises herbes (Lansari, 1985) et les champignons (Paulus, 1990).

Les maladies fongiques du fraisier causent des pertes économiques considérables dans les zones de culture du monde entier. Elles peuvent être divisées en deux classes: dans un groupe sont inclus celles causées par des pathogènes du sol, principalement des espèces de Phytophthora et Rhizoctonia et dans l'autre les maladies causées par des pathogènes aériens tels que les espèces

\section{MATERIEL ET METHODES}

La culture de la fraise est pratiquée dans la localité de Moulay Bouselham, située au sud du Loukkos et délimitant le nord du littoral atlantique de la région du Gharb (à $70 \mathrm{Km}$ au nord de Kénitra et à $35 \mathrm{Km}$ au sud de Larache). La prospection a été organisée durant la compagne de production de la fraise de 2010.

Matériel végétal : Un échantillonnage en diagonal a été effectué au niveau des deux serres visitées dans la localité de Moulay Bouselham. Quinze (15) échantillons de plants de Fraisier malades ont été prélevés et mis dans des sachets en plastique blanc. Tous les échantillons ont été ramenés au laboratoire pour analyse. Parmi les plants de fraisiers, trois ont été placés au réfrigérateur à $4 \pm 1^{\circ} \mathrm{C}$ pendant 2 mois.

Techniques d'analyse des échantillons des différents organes des plantes du fraisier: L'analyse immédiate de la mycoflore associée aux sépales, feuilles, tiges et racines des plants de fraisiers a été réalisée au moyen de la méthode de Buvard de Colletotrichum, Botrytis cinerea, Sphaerotheca macularis and Zythia fragariae (de los Santos et al., 2003).Au Maroc, cette culture est assujettie à plusieurs maladies et ravageurs. Les principales maladies et ravageurs signalés par les agriculteurs sont l'oïdium, les acariens, les noctuelles, le Botrytis, les pucerons et le mildiou (Benicha, 2006). En effet, l'oïdium et la pourriture grise sont signalées comme les deux maladies cryptogamiques les plus importantes au Maroc, causées respectivement par les champignons Sphaerotheca macularis et Botrytis cinerea. Ces deux maladies sévissent durant toute la campagne et peuvent entraîner des dégâts importants en l'absence de stratégie de lutte adéquate (Chtaina et al., 2009). Walali Loudyi et Skiredj (2003) ont signalé en plus des deux premiers pathogènes, Phytophthora cactarum et $P$. fragariae responsables de la maladie du cœur rouge. Au Maroc, aucune étude n'a été réalisée sur les champignons et les maladies fongiques associés à la culture du fraisier. L'objectif de cette première étude est de déterminer la mycoflore qui peut être associée aux symptômes observés sur les différents organes des variétés de fraisier cultivées dans la région du Gharb et le Loukkos (Maroc).

modifiée (Benkirane, 1995). Les feuilles et les tiges présentant différents types de lésions sont prélevées à partir des plants de fraisier. Les fragments de feuilles de $1 \mathrm{~cm}^{2}$ et de tiges de $1 \mathrm{~cm}$ de longueur sont lavés avec l'eau de robinet, puis avec l'eau distillée stérile. Ensuite, ils sont placés stérilement dans des boîtes de Petri contenant 2 rondelles de papier filtre, humidifiés par l'eau distillée stérile. Les boîtes sont ensuite incubées à la lumière continue. Certains fragments de feuilles, ou de tiges, incubés de la même manière que précédemment, sont repiqués dans des boîtes de Petri contenant le milieu P.S.A. (Potato Saccharose Agar ; $200 \mathrm{~g}$ de pomme de terre, $20 \mathrm{~g}$ de saccharose, $15 \mathrm{~g}$ d'Agar-agar, $1000 \mathrm{ml}$ d'eau distillée). Les boîtes sont placées dans un incubateur pendant 7 jours à l'obscurité à $28^{\circ} \mathrm{C}$. Dans le cas des plants placés au réfrigérateur à $4 \pm 1^{\circ} \mathrm{C}$ durant 2 mois, de nombreux sclérotes noirs se sont formés au niveau des feuilles et des tiges sénescentes. Douze (12) sclérotes sont 
récupérés, lavés à l'eau courante puis désinfectés avec l'hypochlorite de sodium à 10\%. Ensuite, ils sont séchés à température ambiante. Ces formes de conservation sont placées dans des boîtes de Petri contenant le milieu de culture P.S.A. Ces boîtes ont été ensuite incubées à l'obscurité à $25^{\circ} \mathrm{C}$ pendant 7 jours. Tandis que pour les fraises montrant des lésions, ils ont été désinfectés avec l'hypochlorite de sodium à $1 \%$. Ensuite, les morceaux de fraises présentant des lésions sont déposés dans des boîtes de Petri contenant le milieu de culture P.S.A. et incubés pendant 7 jours à l'obscurité et à $24^{\circ} \mathrm{C}$. Les racines débarrassées de leur gangue de terre sont lavées à l'eau courante plusieurs fois et à l'eau distillée stérile, puis séchées entre deux feuilles de papier filtre stérile. Les racines sont découpées en petits fragments de 1 à $2 \mathrm{~mm}$, puis déposées stérilement dans des boîtes de Petri contenant l'eau gélosée (15 g d'Agar-Agar, 1000 $\mathrm{ml}$ ). Après incubation à $28^{\circ} \mathrm{C}$ et à l'obscurité pendant $48 \mathrm{~h}$, les colonies apparues sont transférées sur milieu P.S.A. puis incubées aux mêmes conditions pendant 7 jours (Rapilly 1968). L'examen sous microscope optique des différentes cultures et des fragments a permis de déterminer les espèces fongiques à l'aide

\section{RESULTATS}

Les différents organes des plants de fraisier ramenés des fraiseraies de la localité de Moulay Bouselham ont présenté de nombreuses attaques fongiques. Les plus fréquentes sont détectées sur les parties aériennes. Ainsi, des taches foliaires ont été observées sous des formes et des dimensions différentes avec un centre clair et une marge foncée (Figure 1). des clés de détermination de Gilman (1957), Tarr (1962), Ellis (1971), Chidambaram et al. (1974), Domsch et al. (1980) et Champion (1997). Le pourcentage d'infection et/ou de contamination par les différentes espèces fongiques est calculé selon la méthode de Ponchet (1966) qui définit la fréquence d'isolement des différents champignons à partir de 100 lésions ou de 100 pourritures racinaires présentes sur les plantes étudiées selon la formule :

$\mathrm{PC}=(\mathrm{NFI} / \mathrm{NTF}) \times 100$

Où PC est le pourcentage d'infection et/ou de contamination ; NFI est le nombre de lésions infectées par une espèce fongique donnée et NTF est le nombre total de lésions.

Analyse statistique: Le traitement statistique des données a porté sur l'analyse de la variance et le test PPDS (plus petite différence significative). Quand le résultat de l'analyse de la variance enregistre au moins une différence significative au seuil de probabilité de $5 \%$, un test de comparaison des moyennes est appliqué sur ces données. Les pourcentages ont été transformés en Arcsin $\sqrt{ } P$ (où $P$ désigne la proportion du pourcentage).

Des symptômes apparents sur les fraises conduisent à divers types de lésions de formes et de couleurs distinctes, certaines sont circulaires et déprimées brunes ensuite des masses de spores de couleur saumon apparaissent. D'autres fraises, brunissent au début puis se couvrent de fructifications d'abord blancgrisâtre ensuite grise (Figure 2). 
Mouden et al... J. Appl. Biosci. 2013. Mycoflore de quelques variétés du fraiser (Fragaria ananassa L) cultivées en Maroc
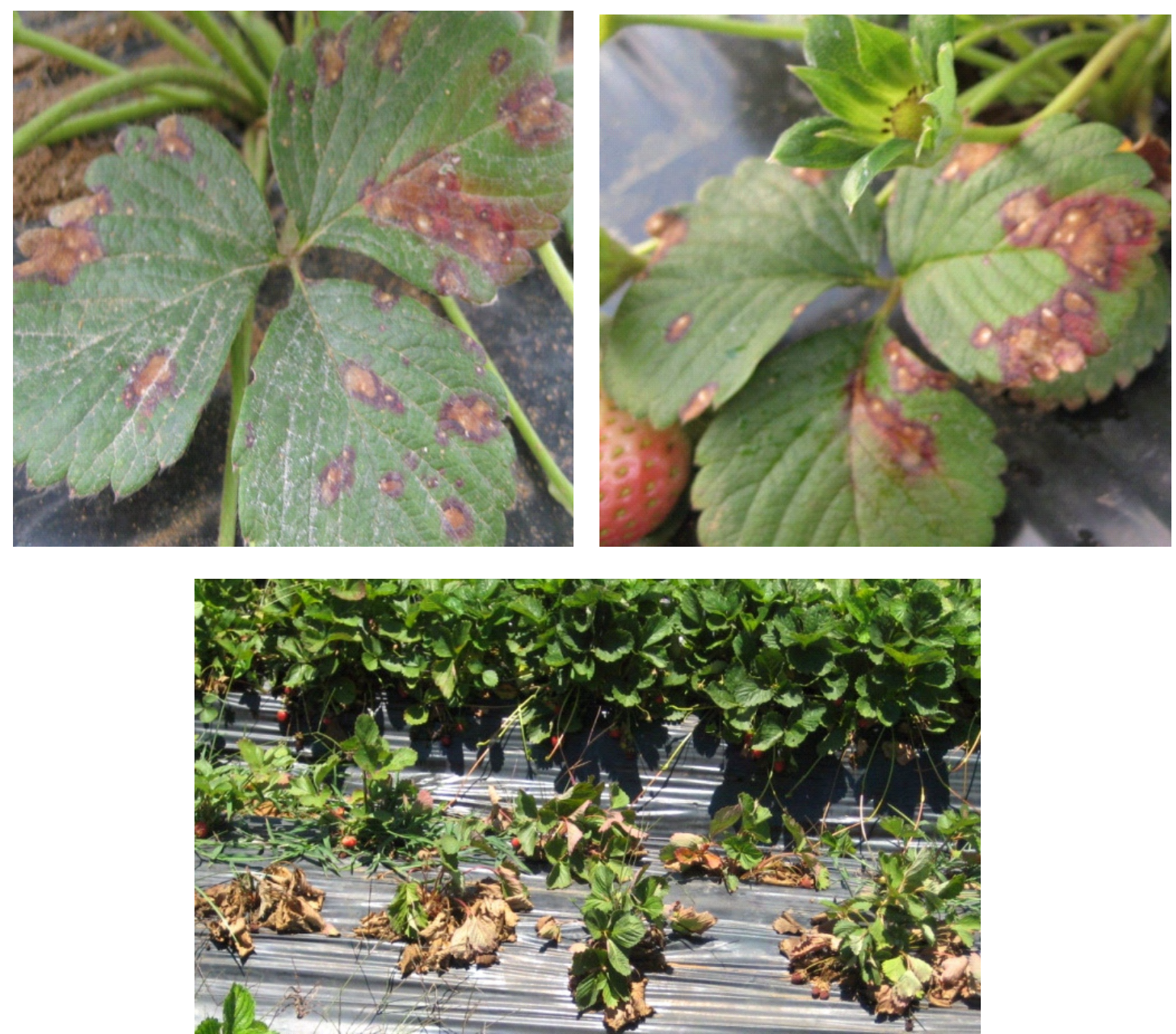

Figure 1. Lésions foliaires et dessèchement des plants de fraisier observés dans une fraiseraie de la localité de Moulay Bouselham.
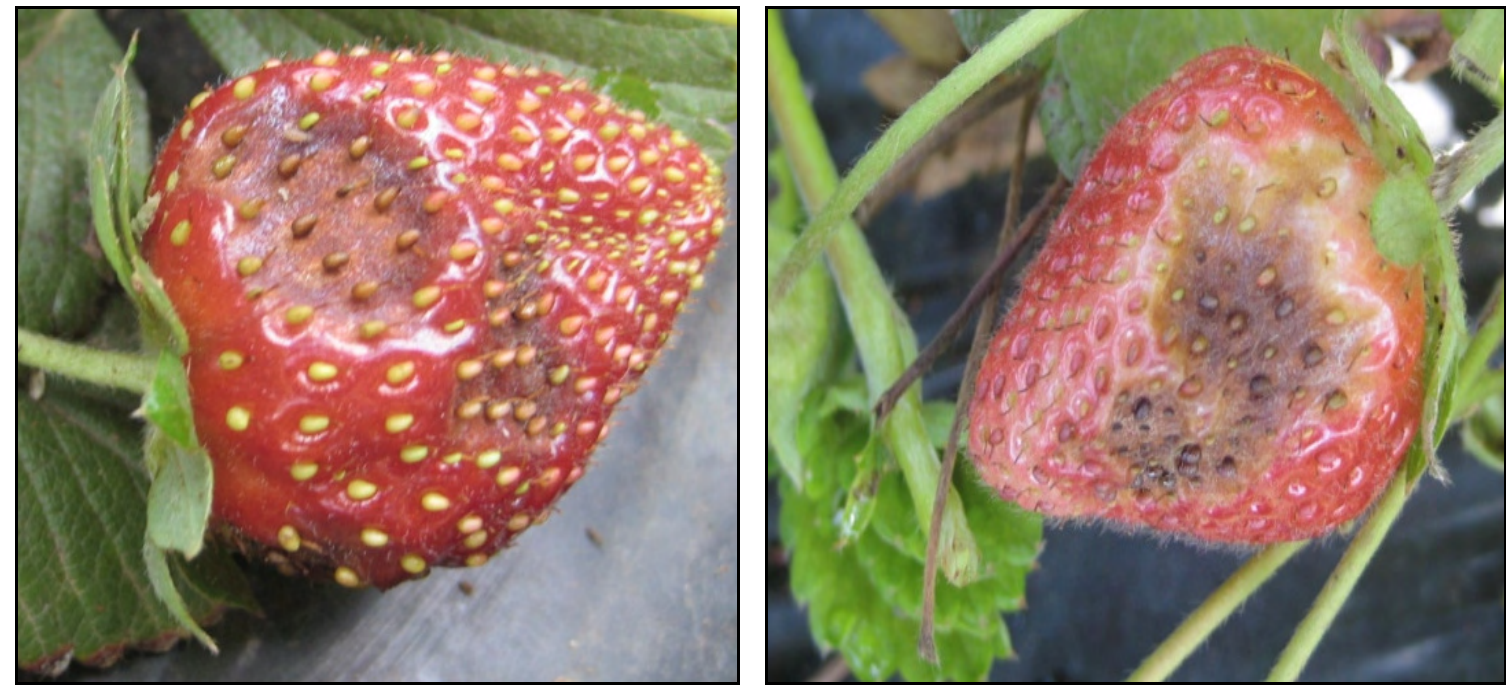


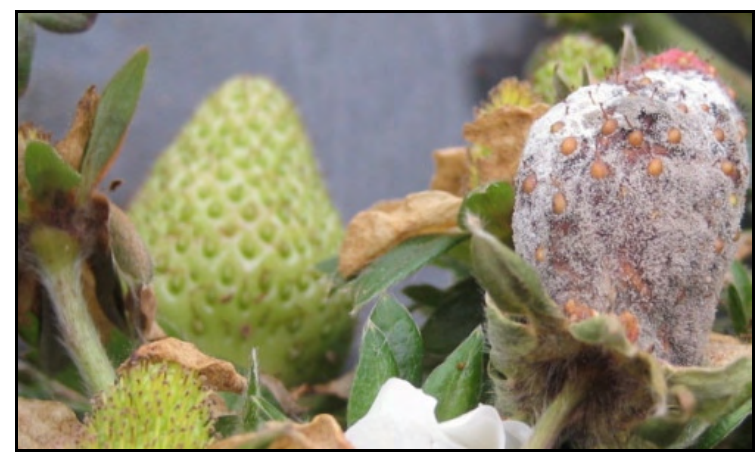

Figure 2. Lésions et pourriture grise des fraises observées dans une fraiseraie de la localité de Moulay Bouselham.

L'examen microscopique des différentes cultures issues des échantillons pris pour analyse a révélé la présence d'un complexe fongique diversifié sur les feuilles, tiges, collet, racines, sclérotes et sur les fruits comportant 17 espèces (Tableau 1). Ces dernières colonisent dans des proportions inégales les parties infectées. Ainsi, les fréquences d'isolement obtenues démontrent une variation reliée à la source d'isolement et aux variétés étudiées (Tableau 2). 
Tableau 1. Mycoflore associée aux différents organes et sclérotes de trois variétés de fraisier cultivées dans la localité de Moulay Bouselham dans la région du Gharb et le Loukkos au Maroc.

\begin{tabular}{|c|c|c|c|c|c|c|c|c|c|}
\hline \multirow[t]{2}{*}{ Espèces fongiques } & \multirow[t]{2}{*}{ Variétés } & \multirow[t]{2}{*}{ Fraises } & \multirow[t]{2}{*}{ feuille } & \multirow[t]{2}{*}{ Tige } & \multirow[t]{2}{*}{ Collet } & \multirow[t]{2}{*}{ Racine } & \multicolumn{2}{|c|}{ Sclérotes } & \multirow{2}{*}{$\begin{array}{l}\text { Nombre } \\
\text { d'isolats }\end{array}$} \\
\hline & & & & & & & Feuille & Tige & \\
\hline \multirow[t]{3}{*}{ Botrytis cinerea } & Camarossa & $\begin{array}{c}\mathrm{BC}_{1}-\mathrm{BC}_{3} \\
\mathrm{Bc}_{2}-\mathrm{Bc}_{4} \\
\mathrm{Bc}_{5}-\mathrm{Bc}_{6} \\
\mathrm{Bc}_{7}\end{array}$ & $\begin{array}{c}\mathrm{Bcf}_{3}-\mathrm{Bcf}_{4-} \\
\mathrm{Bf}_{5}-\mathrm{Bcf}_{6} \\
\mathrm{Bcf}_{7}\end{array}$ & $\begin{array}{l}\text { Bсp1 } \\
\text { Bсp2 } \\
\text { Bсp3 }\end{array}$ & - & - & SCf1 & $\mathrm{SCp}_{1} \mathrm{SCp}_{2^{-}} \mathrm{SCp}_{3^{-}}$ & 19 \\
\hline & Festival & $\begin{array}{c}\mathrm{B}^{\prime} \mathrm{C}_{1}-\mathrm{B}^{\prime} \mathrm{C}_{2} \\
\mathrm{~B}^{\prime} \mathrm{C}_{3}\end{array}$ & $\mathrm{Bcf}_{1}, \mathrm{Bcf}_{2}$ & $\mathrm{Bcp}_{4}$ & - & - & $\mathrm{SCf}_{2} \mathrm{SCf}_{3}$ & $\mathrm{SCp}_{4}$ & 9 \\
\hline & Splander & $B^{\prime} C_{4}-B^{\prime} C_{5}$ & - & $\begin{array}{l}\mathrm{Bcp}_{5^{-}} \\
\mathrm{Bcp}_{6^{-}} \\
\mathrm{Bcp}_{7}\end{array}$ & - & - & $\mathrm{SCf}_{4}$ & $\mathrm{SCp}_{5}$ & 7 \\
\hline \multirow[t]{3}{*}{ Alternaria alternata } & Camarossa & $\mathrm{Aa}_{1}-\mathrm{Aa}_{2}$ & $\begin{array}{l}\text { Aaf }_{1}-\text { Aaf }_{2} \\
\text { Aaf }_{3}-\text { Aaf }_{4}\end{array}$ & Aap $_{1}$ & - & - & - & - & 7 \\
\hline & Festival & $\mathrm{Aa}_{3}$ & Aaf $_{5}-\mathrm{Aaf}_{7}$ & $\mathrm{Aap}_{2}$ & - & - & - & - & 3 \\
\hline & Splander & - & Aaf $_{8}-$ Aaf $_{9}$ & $\mathrm{Aap}_{3}$ & - & - & - & - & 3 \\
\hline \multirow[t]{2}{*}{ Stemphylium botryosum } & Camarossa & - & $\mathrm{Stb}_{1}$ & - & - & - & - & - & 1 \\
\hline & Splander & - & $\mathrm{Stb}_{2}-\mathrm{Stb}_{3}$ & - & - & - & - & - & 2 \\
\hline Gliocladium roseum & Camarossa & - & $\mathrm{Glr}_{1}$ & - & - & - & - & - & 1 \\
\hline Ulocladium atrum & Camarossa & - & $\mathrm{Ula}_{1}-\mathrm{Ula}_{2}$ & - & - & - & - & - & 2 \\
\hline Chaetomium globosum & Camarossa & - & $\mathrm{Chg}_{1}$ & - & - & - & $\mathrm{ChgSC}_{1}$ & $\mathrm{ChgSC}_{2} \mathrm{ChgSC}_{3}$ & 4 \\
\hline Aspergillus nidulans & Festival & - & $\begin{array}{l}\text { Asn }_{1-}^{-} \\
\text {Asn }_{2}\end{array}$ & - & - & - & - & - & 2 \\
\hline \multirow[t]{2}{*}{ Fusarium avenaceum } & Camarossa & Fav $_{1}$ & - & - & - & - & - & - & 1 \\
\hline & Festival & - & - & $\mathrm{Fav}_{2}$ & - & - & - & - & 1 \\
\hline \multirow[t]{2}{*}{ Mucor sp. } & Camarossa & $\begin{array}{l}\mathrm{Mc}_{1} . \mathrm{sp}- \\
\mathrm{Mc}_{2} . \mathrm{sp} \\
\mathrm{Mc}_{3} . \mathrm{sp}\end{array}$ & - & - & - & - & - & - & 3 \\
\hline & Festival & - & - & - & $\mathrm{Mc}_{4} . \mathrm{sp}$ & - & - & - & 1 \\
\hline Verticillium dahliae & Camarossa & $\mathrm{Vd}_{1}$ & - & $\mathrm{Vd}_{2}$ & - & - & - & - & 2 \\
\hline Colletotrichum acutatum & Camarossa & $\mathrm{Cl}_{1-}$ & - & - & - & - & - & - & 1 \\
\hline
\end{tabular}




\begin{tabular}{|c|c|c|c|c|c|c|c|c|c|}
\hline & Festival & - & $\mathrm{Cl}_{2}-\mathrm{Cl}_{3-}$ & - & - & - & - & - & 2 \\
\hline & Splander & - & $\mathrm{Cl}_{4}-\mathrm{Cl}_{5}$ & - & - & - & - & - & 2 \\
\hline Thielavia terricola & Festival & - & $\begin{array}{c}T h_{1-T h_{2}} \\
T h_{3}\end{array}$ & $\mathrm{Th}_{4}$ & - & $\mathrm{Th}_{5}$ & - & - & 5 \\
\hline Stachybotrys atra & Camarossa & - & - & $\mathrm{Sta}_{1}$ & - & $\mathrm{Sta}_{2}$ & - & - & 2 \\
\hline \multirow[t]{2}{*}{ Fusarium oxysporum } & Camarossa & - & Fox $_{1}$ & - & - & - & - & - & 1 \\
\hline & Festival & - & - & $\begin{array}{l}\text { Fox } \\
\text { Fox }\end{array}$ & $\begin{array}{l}\text { Fox } 4 \\
\text { Fox } 5\end{array}$ & $\begin{array}{l}\text { Fox }_{6} \text { Fox7- } \\
\text { Fox8 }\end{array}$ & - & - & 7 \\
\hline \multirow[t]{2}{*}{ Fusarium solani } & Camarossa & - & - & - & $\mathrm{Fsl}_{1}-\mathrm{Fsl}_{2}$ & - & - & - & 2 \\
\hline & Festival & - & - & - & - & $\mathrm{Fsl}_{3}$ & - & - & 1 \\
\hline Fusarium semitectum & Camarossa & - & Fse & - & - & - & - & - & 1 \\
\hline \multirow[t]{2}{*}{ Rhizoctonia solani } & Camarossa & - & - & - & $\mathrm{Rhs}_{2}$ & $\begin{array}{l}\mathrm{Rhs}_{4} \\
\mathrm{Rhs}_{5}\end{array}$ & - & - & 3 \\
\hline & Festival & - & - & $\mathrm{Rhs}_{1}$ & $\mathrm{Rhs}_{3}$ & - & - & - & 2 \\
\hline
\end{tabular}

(-) : espèce non isolée. BC, B'c, Bcf, Bcp, Scf, Scp : Botrytis cinerea; Aa, Aaf, Aap : Alternaria alternata; Stb : Stemphylium botryosum; Gr :Gliocladium roseum; Ula: Ulocladium atrum; Chg, ChgSc: Chaetomium globosum, Asn: Aspergillus nidulans; Fav: Fusarium avenaceum; Mc.sp : Mucor sp ; Vd: Verticillium dahliae; Cl: Colletotrichum acutatum; Th : Thielavia terricola; Sta : Stachybotrys atra; Fox : Fusarium oxysporum ; Fsl : Fusarium solani ; Fse : Fusarium semitectum ; Rhs : Rhizoctonia solani. 
Tableau 2. Fréquence d'isolement exprimée par le pourcentage de contamination et/ou d'infection de différentes espèces fongiques à partir des organes et des sclérotes des plants de trois variétés de fraisier cultivées dans la localité de Moulay Bousselham dans la région du Gharb et le Loukkos.

\begin{tabular}{|c|c|c|c|c|c|c|c|c|}
\hline \multirow[t]{2}{*}{ Espèces fongiques } & \multirow[t]{2}{*}{ Variétés } & \multirow{2}{*}{$\begin{array}{c}\text { Fraises } \\
(\%)\end{array}$} & \multirow{2}{*}{$\begin{array}{c}\text { Feuille } \\
(\%)\end{array}$} & \multirow{2}{*}{$\begin{array}{l}\text { Tige } \\
(\%)\end{array}$} & \multirow{2}{*}{$\begin{array}{c}\text { Collet } \\
(\%)\end{array}$} & \multirow{2}{*}{$\begin{array}{c}\text { Racine } \\
(\%)\end{array}$} & \multicolumn{2}{|c|}{ Sclérotes (\%) } \\
\hline & & & & & & & feuille & tige \\
\hline \multirow[t]{3}{*}{ Botrytis cinerea } & Camarossa & $56,6^{a}$ & $25,3^{\text {cd }}$ & $27,7^{\mathrm{b}}$ & - & - & $29,1^{c}$ & $40,7^{b}$ \\
\hline & Festival & $58,1^{a}$ & $17,9 f$ & $15,4^{d}$ & - & - & 39,8 a & $31,6^{c}$ \\
\hline & Splander & $48,4^{b}$ & - & $41,5^{a}$ & - & - & $23,4^{d}$ & $48,1^{a}$ \\
\hline \multirow[t]{3}{*}{ Alternaria alternata } & Camarossa & $23,4^{\mathrm{d}}$ & $42,03^{a}$ & $11,7^{\text {ef }}$ & - & - & - & - \\
\hline & Festival & $19,8^{\mathrm{e}}$ & $18,7^{f}$ & $13,5^{\text {de }}$ & - & - & - & - \\
\hline & Splander & $22,4^{\text {de }}$ & $23,5^{\text {de }}$ & $15,3^{d}$ & - & - & - & - \\
\hline \multirow[t]{3}{*}{ Stemphylium botryosum } & Camarossa & - & $11,7 \mathrm{~g}$ & - & - & - & - & - \\
\hline & Festival & - & - & - & - & - & - & - \\
\hline & Splander & & $21,9 e$ & - & - & - & - & - \\
\hline Gliocladium roseum & Camarossa & - & $11,06^{g}$ & - & - & - & - & - \\
\hline Ulocladium atrum & Camarossa & - & $22,16^{\mathrm{e}}$ & - & - & - & - & - \\
\hline Chaetomium globosum & Camarossa & - & 11,19 & - & - & - & $32,8^{b}$ & $28,3^{d}$ \\
\hline Aspergillus nidulans & Festival & - & $23,6^{\text {de }}$ & - & - & - & - & - \\
\hline Fusarium avenaceum & Camarossa & $11,1^{f}$ & - & $12,1^{\text {ef }}$ & - & - & - & - \\
\hline \multirow[t]{2}{*}{ Mucor sp } & Camarossa & $31,2^{c}$ & - & - & - & - & - & - \\
\hline & Festival & - & - & - & $19,2 \mathrm{c}$ & - & - & - \\
\hline Verticillium dahliae & Camarossa & $10,5^{f}$ & - & $10,2^{f}$ & - & - & - & - \\
\hline \multirow[t]{3}{*}{ Colletotrichum acutatum } & Camarossa & $10,3^{f}$ & - & - & - & - & - & - \\
\hline & Festival & - & $27,73^{c}$ & - & - & - & - & - \\
\hline & Splander & - & 23,7 de & - & - & - & - & - \\
\hline Thielavia terricola & Festival & - & $32,8^{b}$ & $12,4^{\mathrm{ef}}$ & - & $20,8 c$ & - & - \\
\hline Stachybotrys atra & Camarossa & - & - & $9,8^{f}$ & - & $14,3 d$ & - & - \\
\hline \multirow[t]{2}{*}{ Fusarium oxysporum } & Camarossa & - & $11,2^{g}$ & - & - & - & - & - \\
\hline & Festival & - & - & $24,9 c$ & $44,8 \mathrm{a}$ & $40,3 a$ & - & - \\
\hline \multirow[t]{2}{*}{ Fusarium solani } & Camarossa & - & - & - & - & - & - & - \\
\hline & Festival & - & - & - & $35,5 b$ & $19,1 \mathrm{c}$ & - & - \\
\hline Fusarium semitectum & Camarossa & - & $11,13^{g}$ & - & - & - & - & - \\
\hline \multirow[t]{2}{*}{ Rhizoctonia solani } & Camarossa & - & - & - & $23 c$ & $28,4 b$ & - & - \\
\hline & Festival & - & - & $10,3^{f}$ & $33,3 b$ & - & - & - \\
\hline
\end{tabular}

(-) : espèce non isolée. 
Deux résultats, lus sur la même colonne, diffèrent significativement au seuil de 5\%, s'ils ne sont affectés d'aucune lettre en commun. 
En effet, une présence marquée est notée pour Botrytis cinerea sur les échantillons de fraises, avec un pourcentage de contamination allant de $58,1 \%$ à $56,6 \%$ puis à $48,4 \%$ respectivement sur les variétés Festival, Camarossa et Splander suivie par le genre Mucor à un pourcentage de $31,2 \%$ sur la variété Camarossa. Une atteinte par Alternaria alternata a été également relevée sur Camarossa, Splander et Festival aux pourcentages respectifs $23,4 \%, 22,4 \%$ et $19,8 \%$. Quant aux espèces de Fusarium avenaceum, Verticillium dahliae et Colletotrichum acutatum, leurs pourcentages de contamination restent faibles et significativement différentes des autres espèces. $B$. cinerea, $A$. alternata et Colletotrichum acutatum ont été également isolés à partir des feuilles des variétés de fraisier, avec des pourcentages respectifs de $25,3 \%, 42,03 \%$ sur Camarosa pour les deux premières espèces et $27,7 \%$ sur Festival pour la troisième espèce. Sur les feuilles des plantes de fraisier, de nouvelles espèces se sont installées à savoir Stemphylium botryosum, Ulocladium atrum, Aspergillus nidulans et Thielavia terricola à des pourcentages respectifs de $21,9 \%$ sur Splander, $22,16 \%$ sur Camarosa, $23,6 \%$ et $32,8 \%$ sur festival. Par contre, F. oxysporum, F. semitectum, Gliocladium roseum et Chaetomium globosum sont les moins représentés puisque leurs pourcentages ne dépassent pas $11,7 \%$. Sur les tiges, $B$. cinerea se montre le plus fréquent, son pourcentage de contamination sur la variété Splander est de 41,5\%. La présence d'A. alternata est très réduite ne dépassant pas $15,3 \%$. En revanche, la pourcentage de contamination de $F$. oxysporum s'est élevé à 24,9\% alors que ceux de $F$. avenaceum, $V$. dahliae et $T$. terricola sont inférieurs et significativement identiques $(10,2 \%$ à $12,4 \%)$. Par ailleurs, la présence de Stachybotrys atra est notée au pourcentage de $9,8 \%$ et de Rhizoctonia solani à 10,3\%. $\mathrm{Au}$ niveau du collet, $F$. oxysporum est l'espèce principalement rencontrée sur la variété Festival $(44,8 \%)$ suivie par F. solani $(35,5 \%)$ et de $R$. solani $(33,3 \%)$. Ce champignon a également touché la variété Camarossa (23\%). En effet, F. oxysporum a dominé aussi les espèces retrouvées sur les racines, son pourcentage a atteint $40 \%$ face à $R$. solani, $F$. solani et $T$. terricola présentant respectivement des pourcentages de $28,4 \%, 19,1 \%$ et $20,8 \%$. Sur les sclérotes récupérés des feuilles et des tiges des plants de fraisier, seuls $B$. cinerea et $C$. globosum ont été isolés avec une prédominance significative de $B$. cinerea ayant atteint $48,1 \%$ sur les tiges de Splander et
$39,8 \%$ sur les feuilles de Festival. C. globosum a été isolé aux pourcentages de contamination de $32,8 \%$ et $28,3 \%$ respectivement des feuilles et des tiges de Camarosa. Les caractères morphologiques aussi bien macroscopiques que microscopiques ont été décrits chez les espèces fongiques cultivées sur le milieu de culture Potato saccharose agar.

La colonie de $B$. cinerea peut présenter une apparence blanchâtre qui correspond à l'élongation d'hyphes grêles et hyalins. Toutefois, le mycélium peut produire des touffes de conidiophores (Figure 3 $\mathbf{a}_{1}$ ), dressés étendues, constituant un feutrage intense gris libérant les conidies qui sont ovales, elliptiques ou sphériques (Figure $3 \mathrm{a}_{2}$ ). Lorsque les conditions deviennent défavorables au développement de mycélium et de conidies, des sclérotes se forment. Ils sont constitués d'un mycélium agrégé blanchâtre. En vieillissant, ils durcissent et deviennent noirâtres.

La colonie de Mucor sp. montre un aspect cotonneux avec un mycélium aérien envahissant rapidement toute la boîte de Petri, d'une coloration brun jaune. En vue microscopique, les filaments mycéliens apparaissent siphonnés, les sporocystes sont simples portant des sporocystosphores piriformes contenant de très nombreuses sporocystospores elliptiques libérées par déhiscence du sporocyste ainsi que la columelle (Figure 3b).

Verticillium dahliae a une croissance lente, présentant une colonie de couleur blanc crème. Le mycélium est septé, à texture lisse, le mycélium aérien est peu abondant. Le conidiophore est simple ou ramifié, droit sur lequel apparaît plusieurs nœuds verticillés où sont insérés des sphérules portant chacune une masse de conidies. Ces dernières sont unicellulaires, ovoïdes, ou ellipsoides de très petite taille (Figure $3 c$ ).

Fusarium avenaceum présente une colonie de couleur rose sur le milieu PSA. Le mycélium est cloisonné, hyalin, aérien, et dense. Les macroconidies sont très longues de 5 à 6 cloisons, effilées et courbées vers les deux extrémités avec une cellule basale pédicellée et une cellule apicale allongée (Figure $3 d$ ). Les sporodochies sont colorées en pêche. La colonie de Colletotrichum acutatum est de couleur rose pâle, orange, laissant apparaître de petites masses oranges dispersées dans la culture. L'observation de ces amas permet la distinction des conidies qui sont très nombreuses, fusiformes de 10 à $13 \mu \mathrm{m}$ de longueur et $3 \mu \mathrm{m}$ de largeur (Figure 4e). Le mycélium est aérien, 
Mouden et al... J. Appl. Biosci. 2013. Mycoflore de quelques variétés du fraiser (Fragaria ananassa L) cultivées en Maroc
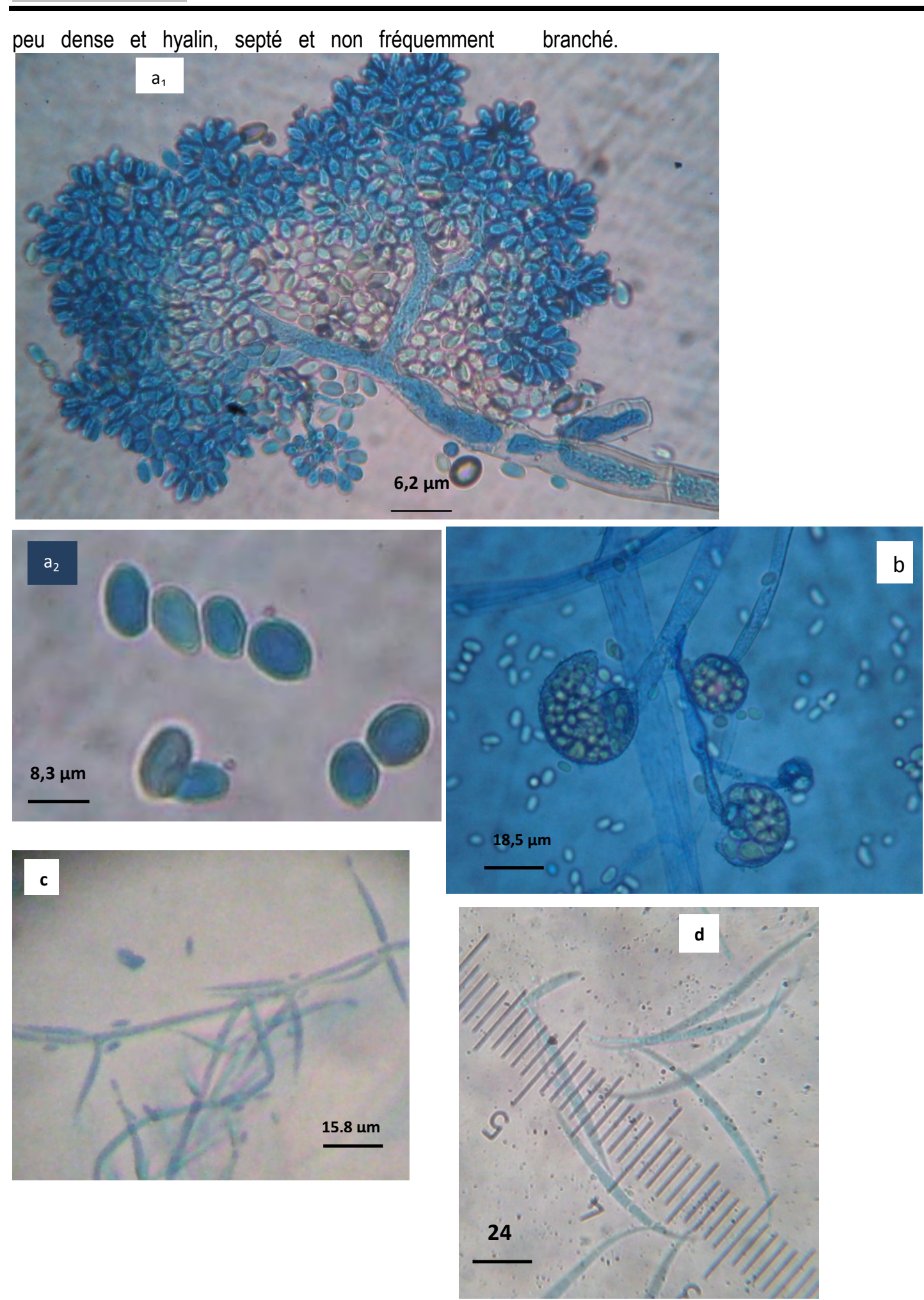


\section{Mouden et al... J. Appl. Biosci. 2013. Mycoflore de quelques variétés du fraiser (Fragaria ananassa L) cultivées en Maroc}

Figure 3. Aspect microscopique des espèces fongiques isolées à partir des fraises. $\mathbf{a}_{1}$ : conidiophore et $\mathbf{a}_{2}$ : conidies de Botrytis cinerea; $\mathbf{b}$ : sporocyste et sporocystospore de Mucor sp.; $\mathbf{c}$ : Verticillium dahliae; d: Fusarium avenaceaum. Grossissement : x 400. Echelle : en $\mu \mathrm{m}$. Liquide de montage : Bleu coton.

Sur le milieu de culture PSA, Stemphyllium botryosum a une croissance rapide, la colonie est de couleur brune ou grise et duveteuse. Le mycélium est septé, pâle à olivâtre claire. Le conidiophore est court, marron clair, comportant un renflement portant la conidie. Les conidies sont solitaires, de couleur brune. Elles sont oblongues à extrémités arrondies largement ellipsoïdes avec généralement des cloisons transversales et longitudinales de 18-23 x 10-13 $\mu \mathrm{m}$ (Figure 4f). Les colonies d'Alternaria alternata sont de couleur noire à noir olivâtre. Les conidiophores sont solitaires ou formant des petits groupes, simples ou ramifiés, droits ou flexibles, souvent géniculés, de couleur olivâtre à brun doré. Les conidies se forment en longueur, souvent branchées en chaîne, ovoïdes ou elliptiques, de couleur pâle à brun doré, lisses ou verruqueuses, mesurant 24-38 x 7-14 $\mu \mathrm{m}$ avec 1 à 8 cloisons transversales, généralement longitudinales ou oblique (Figure 4g)
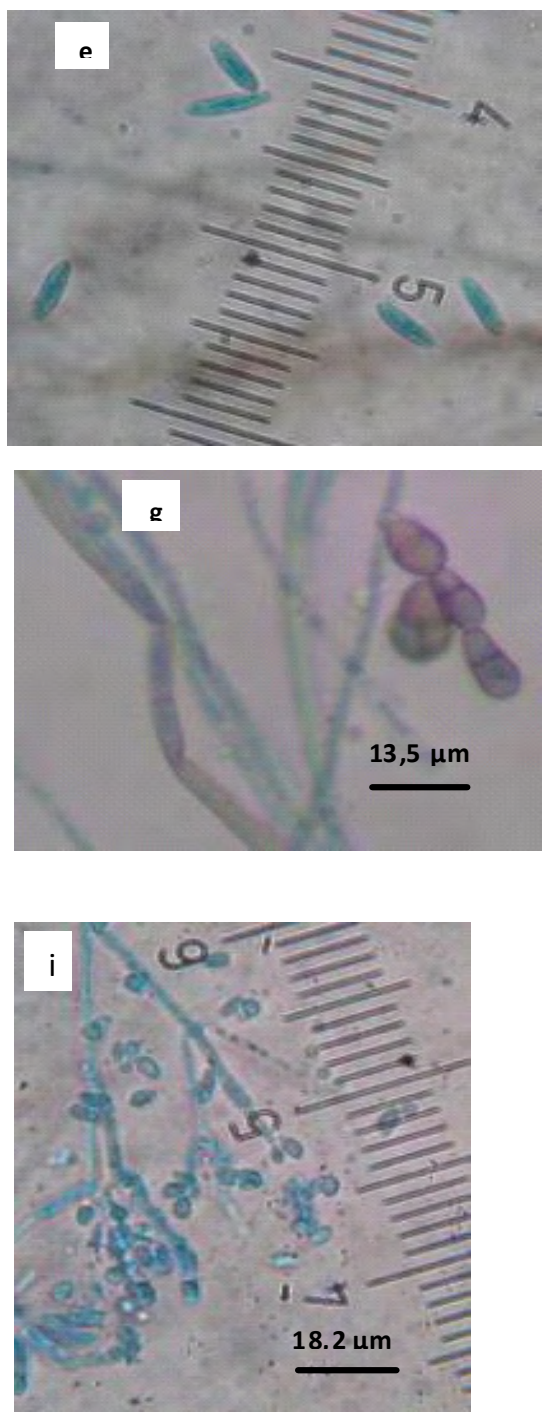
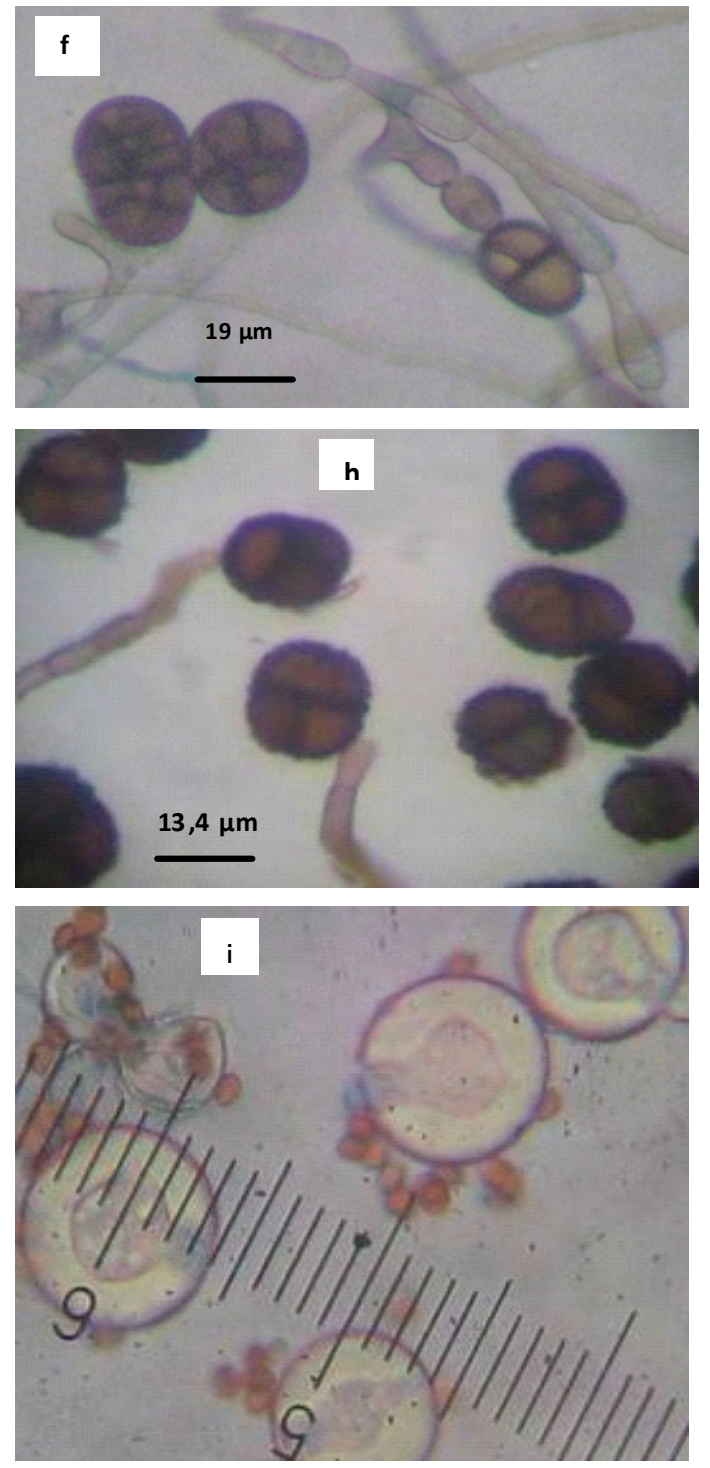

4502 


\section{Mouden et al... J. Appl. Biosci. 2013. cultivées en Maroc}

Figure 4. Aspect microscopique des espèces fongiques isolées à partir des fraises et feuilles de fraisier; e: conidies de Colletotrichum acutatum; $\mathbf{f}$ : Stemphylium botryosum; $\mathbf{g}$ : Alternaria alternata; $\mathbf{h}$ : Ulocladium utrum; i : Gliocladium roseum; j: Aspergillus nidulans. Grossissement : $x$ 400. Echelle : en $\mu \mathrm{m}$. Liquide de montage : Bleu coton.

Ulocladium atrum a une croissance rapide, couvrant la surface du milieu PSA après dix jours d'incubation à $28^{\circ} \mathrm{C}$, d'une couleur vert foncé à l'état jeune devenant noirâtre avec le temps, d'un revers noir et d'un aspect lisse. Le mycélium est généralement enfoncé dans le milieu de culture, cloisonné, brun. Le conidiophore très souvent géniculé, brun et de 3 à $5 \mu \mathrm{m}$ d'épaisseur. Les conidies sont solitaires souvent sphériques, à paroi épaisse et ornementée, de couleur marron. Elles ont des cloisons très épaisses, avec une cloison transversale et une autre longitudinale de $13-30 \times 12$ $23 \mu \mathrm{m}$ (Figure 4h). Sur le milieu PSA, Gliocladium roseum a une colonie blanche à saumon. Les conidiophores sont ramifiés, branchés de $45-125 \mu \mathrm{m}$ de longueur en forme de pinceau. Les fructifications conidiennes sont portées par des phialides, elles sont hyalines, lisses de forme ellipsoïdale et de 5-7 x 3-5 $\mu \mathrm{m}$ de diamètre (Figure 4i).

Sur le milieu P.S.A, la colonie d'Aspergillus nidulans a une croissance rapide, de couleur vert haricot à l'état jeune avec des secteurs bruns, d'un revers brun et d'un aspect plat. Les secteurs bruns sont constitués de cleistothécies abondants d'Emericella nidulans, téléomorphe de l'espèce, qui se développent parfois au dessus des formes conidiales couvrant ainsi toute la culture. Elles sont sphériques de couleur pourpre et renfermant des asques à 8 ascospores qui sont lenticulaires à paroi lisse (Figure 4j). Chaetomium globosum, présente une colonie à croissance rapide sur PSA couvrant toute la surface du milieu de culture après 10 jours d'incubation à $28^{\circ} \mathrm{C}$, d'une couleur vert clair à l'état jeune, Des périthèces apparaissent et deviennent de plus en plus nombreux et sombres sur les cultures âgées (Figure $5 \mathbf{k}_{1}$ ). Leur ouverture permet la libération des asques (Figure $5 \mathbf{k}_{3}$ ) contenant des ascospores sphériques de couleur vert foncé et de 8-10 $x 6,5 \mu \mathrm{m}$ de diamètre (Figure $5 \mathbf{k}_{2}$ ). Thielavia terricola présente une colonie blanche avec un mycélium aérien, cotonneux, peu développé. Après 10 jours d'incubation à $28^{\circ} \mathrm{C}$, apparaissent d'abondants boutons noirs de très petite taille appelés les cleisthotèces. La vue microscopique montre que ces structures sont circulaires avec absence d'ostiole et d'appendice. Leur paroi est sombre, composée de 2 à 3 couches cellulaires à paroi épaisse (Figure $5 I_{1}$ ). L'ouverture de ces structures permet la sortie des asques qui sont ovoïdes à paroi mince comportant 8 ascospores. Ces derniers sont fusiformes ou ellipsoïdes légèrement pointus aux deux extrémités d'une couleur marron claire et de 10-13 x 6-7 $\mu \mathrm{m}$ de diamètre (Figure $5 I_{2}$ ).

La colonie de Fusarium semitectum Berk. et Ravenel 1875 a une croissance rapide, présentant un mycélium aérien abondant de couleur brune jaunâtre. Les microconidies sont rares. Les macroconidies sont droites ou légèrement curvées (Figure $5 n$ ).

Le mycélium de Fusarium oxysporum Schltdl (1824) est aérien, abondant et de couleur blanche. Lorsque les chlamydospores sont abondantes, le mycélium devient de couleur violette ou bleu, mais devient marron jaunâtre lorsque les sporodochies sont abondantes. La croissance mycélienne est rapide. Les microconidies sont généralement abondantes, portées par des phialides simples et courtes ou sur un conidiophore branché, généralement unicellulaires, ellipsoïdes à cylindriques, droites ou curvées. Les macroconidies sont fusiformes, légèrement curvées ou arquées, pointues aux extrémités (Figure $5 \mathrm{~m}$ ). La colonie de Fusarium solani (Mart.) Sacc. 1881 croit rapidement avec un mycélium abondant. Les microconidies sont peu abondantes avec une seule cellule. Les macroconidies sont de grande taille, cloisonnées de 3 à 5 cloisons. Les deux surfaces de la spore sont parallèles et les deux cellules apicales et basales sont légèrement bombées (Figure 50 1 ). Les chlamydospores sont solitaires $(7,3 \mu \mathrm{m})$ ou par paire de 8 à $10,6 \mu \mathrm{m}$ de longueur, abondants, leur paroi est lisse (Figure $6_{02}$ ).

Sur le milieu PSA, Stachybotrys chartarum montre une croissance lente, avec un mycélium fin d'une couleur blanche au début devenant noire avec le temps, d'un revers noir et d'un aspect lisse. Le conidiophore est cloisonné, simple ou branché en angles droits, hyalin devenant brun avec l'âge. Les conidies naissent solitairement, elles sont unicellulaires et elliptiques ou sub-sphériques dépourvues d'ornementations et de couleur brune de 7- $9 \mu \mathrm{m} \times 4-6 \mu \mathrm{m}$ de diamètre (Figure $6 p$ ). La colonie de Rhizoctonia solani est de couleur 
Mouden et al... J. Appl. Biosci. 2013. Mycoflore de quelques variétés du fraiser (Fragaria ananassa L) cultivées en Maroc

brune, à croissance rapide. Son mycélium est abondant, de couleur brunâtre à brun foncé. II est constitué d'hyphes relativement épais et il est embranchements partent à angles droits (Figure $6 \mathbf{q}_{1}$ ). Une culture âgée laisse apparaître plusieurs sclérotes caractérisé par un aspect réticulé dont les dont la taille est de 1-3 mm (Figure $6 \mathbf{q}_{2}$ ). 


\section{Mouden et al... J. Appl. Biosci. 2013. Mycoflore de quelques variétés du fraiser (Fragaria ananassa L)}

cultivées en Maroc
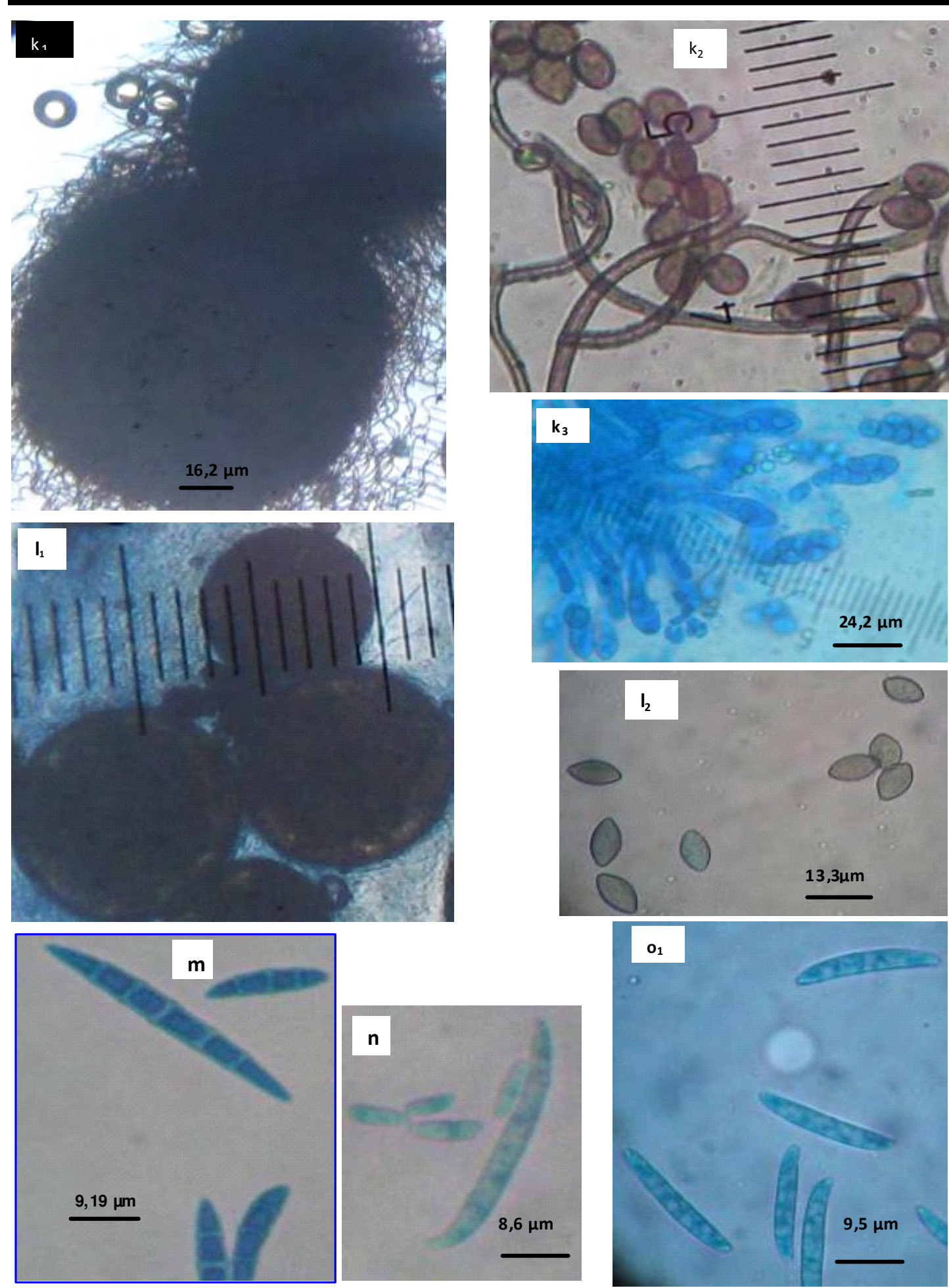

Figure 5. Aspect microscopique des espèces fongiques isolées à partir de divers organes végétatifs de Fragaria ananassa appartenant à deux variétés « Camarosa » et« Festival ». (k k: périthèce de Chaetomium globosum, $\mathbf{k}_{2}$ : ascospore, $\mathbf{k}_{3}$ : asque ; $\mathbf{l}_{1}$ : Cleisthotécie, $\boldsymbol{l}_{2}$ ascospores de Thielavia terricola $; \mathbf{m}$ : Fusarium semitectum $; \mathbf{n}:$ Fusarium oxysporum ; $\mathbf{0}$ : macroconidies de Fusarium solani; Grossissement : $x$ 400. Liquide de montage : Bleu coton. 

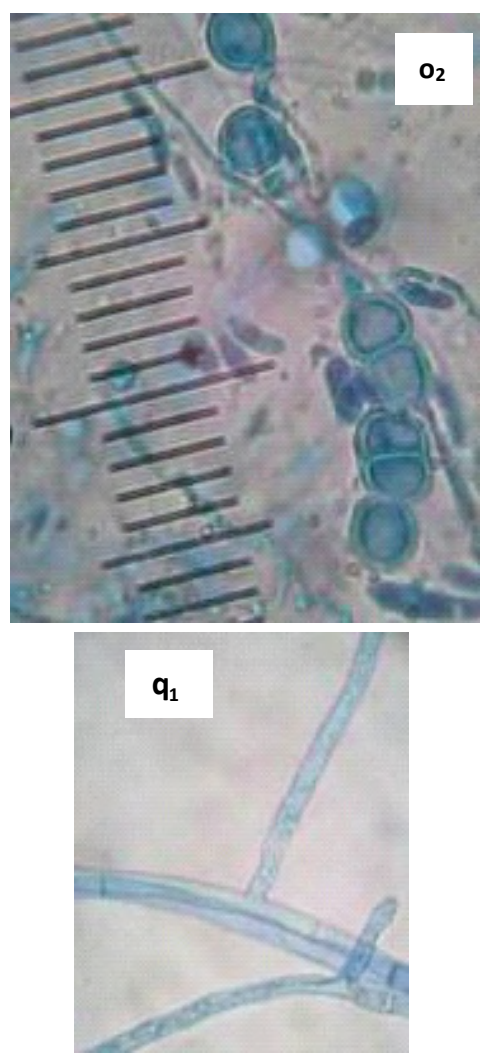
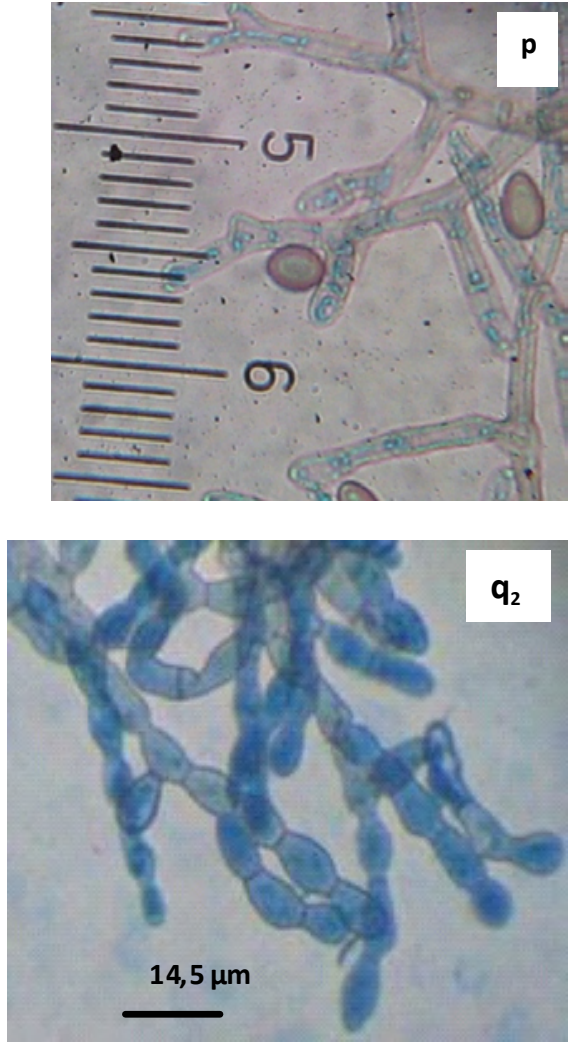

Figure 6. Aspect microscopique des espèces fongiques isolées à partir de divers organes végétatifs de Fragaria ananassa appartenant à deux variétés « Camarosa » et « Festival ». $\mathbf{0}_{2}$ : Chlamydospores de F. solani; $\mathbf{p}$ : Stachybotrys chartarum; $\mathbf{q}_{1}$ : Mycélium et $\mathbf{q}_{2}$ : Surface des sclérotes de Rhizoctonia solani; Grossissement : x 400. Liquide de montage : Bleu coton.

\section{DISCUSSION ET CONCLUSION}

L'analyse mycologique des plants de fraisier collectés dans la localité de Moulay Bouselham a montré que certaines espèces fongiques isolées ont été déjà signalées dans le monde (Maas, 1984), alors que d'autres sont rencontrées pour la première fois sur cette culture au Maroc. Les fréquences les plus importantes ont été relevées sur les fraises, les feuilles et les tiges ainsi que sur les sclérotes. Les lésions observées sur les parties aériennes du fraisier ont été dominées surtout par $B$. cinerea suivie par $A$. alternata. En effet, $B$. cinerea a été signalée sur diverses cultures d'importance agronomique comme la vigne (Mackenzie et al., 2003, Gabriolotto et al., 2009) ), le fraisier (Schmid et al., 2005), la tomate (O'neill et al., 1997, Mouria, 2009), la laitue (Beneden et al., 2009) et des plantes ornementales comme Rosa hybrida (Araújo et al., 2005). Ce champignon entraine le brunissement des fleurs et la pourriture des fruits, mais aussi le brunissement et la pourriture des feuilles, les chancres et la pourriture des bulbes, des tubercules et des racines et même la fonte de semis (Hausbeck et Moorman, 1996). De même, Alternaria alternata est très redoutée chez de nombreuses cultures et plantes ornementales. Elle provoque des dégâts sur les feuilles de Morinda citrifolia (Hubballi et al., 2010), du pistachier (Pryor et Michailides, 2002), sur des fruits de poirier et de pomme (Biggs, 1994, Terakami et al., 2007). Sur fruits et feuilles de néflier Eriobotrya japonica (Batta, 2005). Les infections latentes de ce champignon peuvent également se produire et entraîner par conséquent des maladies de post-récolte sur poirier (Maouni et al., 2007) ou sur des variétés de Citrus (Masunaka et al., 2005). Wada et al. (1996), l'ont isolé à partir des pétioles et des feuilles de trois variétés de fraisier. Selon Saber et al. (2003), B. cinerea et $A$. alternata constituent les agents fongiques les plus redoutables sur les fraises. Deux autres agents fongiques ont été moyennement représentés à savoir 
Mucor sp. et Colletotrichum acutatum. D'après Lowings (1956), le genre Mucor a été rapporté comme un pathogène de post récolte des fraises. Mucor piriformis et Mucor mucedo ont été signalés sur la tomate (Moline et Kuti, 1984). A propos de Colletotrichum acutatum, il a été signalé comme principal agent causal de l'anthracnose du fraisier (Smith et al., 1990 ; Howard et al., 1992). Les fruits et les feuilles sont les plus touchés par ce champignon. De même, Xue et Davidson (1995) ont noté une incidence sur les fruits de $11 \%$ à $82 \%$ relatifs à deux variétés de fraisier. Selon Freeman et Katan (1997), ce pathogène a beaucoup d'importance à cause des infections qu'il peut engendrer sur les fruits, stolons, collets et racines.

Stemphylium botryosum est présent sur un grand nombre de plantes et à répartition géographique très étendue. Au Maroc, cette espèce n'a jamais été isolée préalablement à partir des feuilles des plantes de fraisier. En Californie, il a été détecté pour la première fois sur les feuilles des épinards (Spinacia oleracea $L$.) (Koike et Henderson, 2001). Selon ces auteurs, au début de l'attaque, les lésions sont circulaires de 2 à 5 $\mathrm{mm}$ de diamètre, de couleur vert grisâtre puis les taches deviennent plus larges et de couleur jaunâtre. Hernandez-Perez et du Toit (2006) ont également pu isoler ce champignon à partir des semences des épinards. Des légumineuses comme la luzerne (Medicago sativa L.) se sont montrées susceptibles à l'infection par Stemphylium botryosum. Irwin (1984) avait décrit les symptômes de la maladie par la présence des lésions foliaires circulaires à irrégulières, blanches au centre et entourées de marges marron foncées. Une diminution de $62 \%$ de rendement de lentille (Lens culinaris Medik.) a été rapportée en Inde et au Bengladesh suite à l'attaque par l'agent causal de la défoliation Stemphylium botryosum (Mwakutuya, 2006). En Egypte, des plantes d'oignon, ont été lourdement affectées par ce pathogène et ont manifesté des symptômes de brûlure au niveau des feuilles, tiges et semences (Hussein et al., 2007).

Cette étude a pu déceler la présence de plusieurs champignons ayant une grande aptitude à contrôler certaines infections fongiques par le biais de leur action antagoniste. C'est le cas de Gliogladium roseum utilisé comme agent de lutte biologique vis-à-vis de certains agents pathogènes affectant plusieurs cultures comme Botrytis cinerea sur framboisier (Yu et Sutton, 1998) et sur concombre (Moody et Gindrat, 1977) ou Sclerotinia sclerotiorum sur chou (Rabeendran et al., 1998). Au Mexique, ce champignon a été signalé comme agent causal de la pourriture de la tige souterraine des plantes de Gladiolus grandiflorus (González-Pérez et al., 2008), ainsi qu'au japon, où il a été retrouvé sur des plantes de Trifolium pratens L. (Christensen et al., 1994). De même, Huang et Erickson (2007) ont rapporté l'efficacité d'Ulocladium atrum à réduire l'incidence et la sévérité de la pourriture blanche d'haricot causée par Sclerotinia sclerotiorum. Selon KÖhl et al. (1995), cet agent saprophyte est doté d'un pouvoir compétitif vis-à-vis des saprophytes colonisant les feuilles de Lilium longiflorum Thumb. tel que Cladosporium spp. et réduit considérablement la sporulation de Botrytis cinerea envahissant les tissus nécrosés. Son antagonisme vis-à-vis de Botrytis cinerea a été observé également sur les feuilles de Cyclamen persicum L. (Köhl et al., 1998) et des plantes du Géranium Pelargonium zonale (Gerlagh, 2001).

Des isolements effectués à partir du sol dans des plantations d'Ananas (Ananas comosus) en Thailand (Pornsuriya et al., 2008) ont mis en évidence la présence de Chaetomium globosum. En Iran, ce champignon figure parmi les cryptogames colonisant les grains de blé au cours de leur stockage (Gohari et al., 2007). II est également impliqué dans la lutte biologique contre plusieurs agents pathogènes comme Pythium ultimum (Di Pietro et al., 1992) et Botrytis cinerea (Köhl et al., 1998). Une formulation à base de Chaetomium globosum a été conçue comme étant une substance hautement antagoniste vis-à-vis de Fusarium oxysporum responsable de la flétrissure de la tomate (Charoenporn et al., 2010). Aspergillus nidulans se présente selon Sibounnavong et al. (2009) comme un antagoniste fongique prometteur contre Fusarium oxysporum f. sp. lycopersici. Une activité antagoniste a été prouvée par ce champignon vis-à-vis de Colletotricum gloeosporioides agent causal de l'anthracnose de Vanilla planifoli (Talubnak et Soytong, 2010). La majorité des isolats de Verticillium dahliae sont caractérisées par la formation de microsclérotes sur le milieu de culture ou dans le sol. Seulement l'espèce isolée n'a pas produit de microsclérotes. En Tunisie, Jabnoun et al. (2010) ont mis en évidence l'existence des isolats dépourvus également de microsclérotes. En effet, le fraisier n'est pas épargné de l'attaque par ce pathogène (Lockhart et al., 1969). II est destructif dans les substrats clairs sablonneux des régions productrices de fraisier en Australie (Steffek et al., 2006). Selon Guillemond et al. (2006), ce parasite altère essentiellement les tissus vasculaires induisant dans la majorité des cas le flétrissement chez de 
nombreuses espèces végétales géographiquement distinctes. Verticillium dahliae affecte des cultures de tomate dont l'incidence moyenne de maladie a été de l'ordre de $59 \%$ en Tunisie (Jabnoun et al., 2007). La flétrissure des plantes de tomate est due selon Kim et al. (2001) à V. dahliae. D'après Vallad et al. (2005), la dissémination et la contamination par ce champignon se produisent au moyen des semences chez la laitue. D'autre part, Devay et al. (1997), ont observé une déficience en potassium au niveau des pétioles des plants de cotton (Gossypium hirsutum) attaqués par Verticillium dahliae.

Thielavia terricola a été présente sur les feuilles, tiges et racines accompagnant les Fusarium et Emercilla nidulans. Ainsi, une étude a signalé la présence de ce cryptogame en compagnie d'autres champignons ayant envahi les racines de tournesol comme Fusarium, Emercilla, Penicillium reliés par leur production des inulases (Souza-Motta et al., 2003). Le genre Fusarium a été amplement représenté dans cette étude. 5 espèces ont été identifiées avec une prédominance de Fusarium oxysporum. Ce pathogène a été signalé sur le fraisier sous une forme spécialisée connue par Fusarium oxysporum f. sp. fragariae (Hyeon et al., 2009). Il a été rencontré également sur le bananier (Musa accuminata L.) (Meddah et al., 2010) et sur des plantes d'Hibiscus rosa-sinensis où il est présent sous forme de dômes de couleur orange sur les tiges et les branches de cette plante hôte (Meddah et al., 2006).

Quant à Fusarium solani, il n'a jamais été cité auparavant sur les plantes de fraisier mais il s'attaque à d'autres cultures comme le coton (Abd-Elsalam et al., 2007), Dalbergia sissoo Roxb chez qui il provoque un brunissement interne des tiges et des racines (Rajput et al., 2008). Bhanumathi et Rai (2007) ont rapporté également Fusarium solani comme l'agent pathogène le plus important des racines infectées d'haricot (Phaseolus vulgaris L.). II a été rencontré dans la mycoflore associée au bananier (Musa accuminata L.) (Meddah et al., 2010). Fusarium avenaceum a été signalé pour la première fois sur le fraisier, il est très commun sur les céréales. Ce champignon, a été associé aux espèces de Fusarium responsables de la pourriture de la couronne de blé et d'orge (Backhouse et al., 2004). Xue et al. (2006) l'ont signalé comme moyennement pathogène sur l'orge. II a été identifié également chez le broccoli comme un nouveau pathogène qui se développe durant l'entreposage prolongé à basse température et sous atmosphère contrôlée (Mercier et al., 1991). Son potentiel comme agent de lutte biologique est discutable contre les espèces de mauvaises herbes du genre Rubus (Oleskevich et al., 1998).

Fusarium semitectum est une espèce à très large gamme d'hôtes, elle s'attaque aux plantes ornementales tels que Hibiscus rosa-sinensis (Norse, 1974) et Pelargonium sp. (Ebbels et Allen, 1979). Elle affecte différentes espèces de bananiers (Williams et Liu, 1976 ; Wallbridge, 1981 ; Shivas, 1989 ; Meddah et al., 2010). Ce champignon a été également isolé des semences de Vigna unguiculata (Rodrigues et Menezes, 2006), Gossypium hirsutum (Costa et al., 2005) et Dalbergia sissoo (Gupta et al., 2011) chez lesquels il est capable de provoquer des altérations sur les jeunes plantules. II a aussi été identifié comme étant l'agent causal de chancres sur les rameaux du noyer (Juglans regia) (Seta et al., 2004 ; Belisario et al., 2010).

Stachybotrys chartarum est une moisissure poussant essentiellement sur la paille et le foin stockés dans des conditions d'humidité excessives. II est souvent isolé des matériaux de construction avec des problèmes d'humidité. Li et Hartman (2000) l'ont isolé à partir des racines de soja où il s'est également montré pathogène. De sévères infections conduisant à la mort du feuillage et la pourriture des pousses voire la mortalité de la plante entière ont été observées sur Tillandsia tenuifolia suite à l'attaque par Stachybotrys chartarum (Zhao et al., 2010).

Rhizoctonia solani est l'espèce pathogène la plus importante du genre Rhizoctonia. Elle s'attaque à une vaste gamme de cultures horticoles, céréalières ou ornementales et elle est présente dans la plupart des sols cultivés du monde. II est l'agent causal de la brûlure de la gaine foliaire du riz (Sundravadana et al., 2007). II s'attaque aussi aux semences de coton (Gossypium hirutum L.) (Armentrout et Downer, 1987). II est responsable de la fonte de semis des plantes de tomate (Jiskani et al., 2007). Suite à l'attaque par Rhizoctonia solani, des plants de fraisiers manifestent des symptômes de type rabougrissement des folioles, stolons et pétioles et la plupart du temps des racines nécrosées (Tanaka et al., 1995). Les investigations menées dans la localité de Moulay Bouselham confirment l'attaque des plants de fraisier par ce pathogène au niveau de la tige, du collet et des racines.

Les résultats obtenus indiquent la présence d'un complexe fongique assez diversifié comportant des 
espèces dotées d'un grand pouvoir antagoniste, d'autres ont un pouvoir pathogène sur plusieurs cultures et certains sont des parasites de faiblesse. La colonisation des différents organes végétatifs des plants de fraisiers par ces espèces fongiques peut avoir des conséquences sur leur état sanitaire, leur survie et leur rendement dépendants des mesures phytosanitaires exposées aux réticences des marchés
Européens vis-à-vis de l'usage des produits chimiques. Ainsi, un traçage de l'évolution de la flore fongique et l'examen comparée des plants avant et après transplantation pourrait déterminer l'origine des infections survenues sur les plantes cultivées et permettrait l'adoption des méthodes de lutte plus adaptées et opportunes.

\section{REMERCIEMENTS}

Ce travail a bénéficié du programme national d'appui à la recherche sectorielle, projet RS-23, financé par le Centre National de la Recherche Scientifique et Technique, Rabat, Maroc.

\section{REFERENCES BIBLIOGRAPHIQUES}

Abd-Elsalam K. A., Omar M. R., El-Samawaty A. and Aly A. A., 2007. Response of commercial cotton cultivars to Fusarium solani. The Plant Pathology Journal (The Korean Society of Plant Pathology) 23 (2): 62-69.

Anonyme, 2006. Diagnostic Xanthomonas fragariae. EPPO Bulletin 36 (1): 135-144.

Anonyme, 2010. Dossier du mois: Le marché mondial de la fraise. Actualité Export, Revue Trimestrielle-Campagne 2010-2011 de I'Etablissement Autonome de Contrôle et de Coordination Des Exportations 30: 17-20.

Anonyme, 2012. FAOSTAT, FAO Statistics Division. URL/faostat.fao.org/consulté le 29 juillet 2012.

Araújo A. E., Maffia L. A., Mizubuti E. S. G., Alfenas A. C., Capdeville G. and Grossi J. A. S., 2005. Survival of Botrytis cinerea as mycelium in rose crop debris and as Sclerotia in soil. Fitopatologia Brasileira 30: 516-521.

Armentrout V. N. and Downer A. J., 1987. Infection cushion development by Rhizoctonia solani on cotton. Phytopathology 77 (4): 619-623.

Atta Aly M. and Ezzat M. A., (1999). Reducing quality loss of strawberries during local marketing and exportation by using different cool chains In Gerasopoulos D. (ed.). Post-harvest losses of perishable horticultural products in the Mediterranean region. Chania: CIHEAM-IAMC, Cahiers Options Méditerranéennes 42: 35-47.

Backhouse D., Abubakar A. A., Burgess L. W., Dennis J. I., Hollaway G. I., Wildermuth G. B., Wallwork H. and Henry F. J., 2004. Survey of Fusarium species associated with crown rot of wheat and barley in eastern Australia. Australasian Plant Pathology 33 (2): 255-261.
Bamouh A., Ezzahouani A. and Chamekh A., 2012. Conduite culturale du fraisier au Maroc. Agriculture du Maghreb 56: 52-61.

Batta Y., 2005. Control of Alternaria Spot Disease on Loquat (Eriobotrya japonica Lindl.) Using Detached Fruits and Leaf-disk Assay. AnNajah University Journal Research (N.Sc.) 19: 70-82.

Belisario A., Luongo L., Vitale S. and Santori A., 2010. First report of Fusarium semitectum as the agent of twig cankers on Persian (English) Walnut in Italy. Plant Disease 94 (6): 791.

Beneden S. V., Pannecoucque J., Debode J., De Backer G. and Höfte M., 2009. Characterisation of fungal pathogens causing basal rot of lettuce in Belgian greenhouses. European Journal of Plant Pathology 124 (1): 9-19.

Benicha M., 2006. Mode d'utilisation des pesticides sur la culture du fraisier dans le périmètre $d u$ Loukkos. Bulletin trimestriel d'information du Centre Régional de la Recherche Agronomique de Tanger, Tawassol 12: 1-4.

Benkirane R., 1995. Contribution à l'étude des maladies du riz au Maroc. Cas de la pyriculariose due à Pyricularia oryzae. Thèse

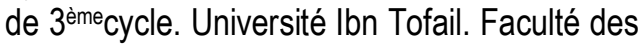
Sciences, Kénitra, Maroc, 145p..

Bhanumathi A. and Rai V. R., 2007. Leaf blight of Azadirachta indica and its management in vitro. African Journal of Agricultural Research $2(10): 538-543$.

Biggs A. R. 1994. Mycelial growth, sporulation and virulence to apple fruit of Alternaria alternata isolates resistant to iprodione. Plant Disease 78 (7): $732-735$. 
Bull C. T., Huerta A. I. and Koike S. T., 2009. First report of blossom blight of strawberry (Fragaria $x$ ananassa) caused by Psendomonas marginalis. Plant Disease 93 (12): 1350.

Champion R., 1997. Identifier les champignons transmis par les semences. INRA, Paris, 398 p.

Charoenporn C., Kanokmedhakul S., Lin F. C., Poeaim S. and Soytong K., 2010. Evaluation of bioagent formulations to control Fusarium wilt of tomato. African Journal of Biotechnology 9 (36): 5836-5844.

Chevaugeon J., 1951. Une fusariose du piment en Côte d'Ivoire. Revue de Mycologie, France, Supplément Colonial 16 (1): 81-86.

Chidambaram P., Mathur S. B. and Neergaard P., 1974. Identification of seed-borne Drechslera species. Handbook on Seed Health Testing, series $2 \mathrm{~B}(3)$ : 165-207.

Christensen M. J., Koga H., Tsukiboshi T. and Uematsu T., 1994. Possible causes of poor persistence of red clover stands in Japan. Bulletin of National Grassland Research Institute 49: 4350.

Chtaina N., Doudouche M., Dadi A. and Zdeg J., 2009. Gestion des problèmes phytosanitaires du fraisier au Maroc selon le référentiel de qualité Global Gap et difficultés d'application. Proceedings Colloque International sur la gestion des risques phytosanitaires, Marrakech, Maroc, 9-11 Novembre, Volume I: 65-69.

Costa M. L. N., Dhingra O. D. and da Silva J. L., 2005. Influence of internal seedborne Fusarium semitectum on cotton seedlings. Fitopatologia Brasileira 30 (2): 183-186.

De Los Santos B., Barrau C. and Romero F., 2003. Strawberry fungal diseases. Food, Agriculture and Environment 1 (3 and 4): 129-132.

DeVay J. E., Weir B. L., Wakeman R. J. and Stapleton J. J., 1997. Effects of Verticillium dahliae infection of cotton plants (Gossypium hirsutum) on potassium levels in leaf petioles. Plant Disease 81 (9): 1089-1092.

Di Pietro A., Gut-Rella M., Pachlatko J. P. and Schwinn F. J., 1992. Role of Antibiotics Produced by Chaetomium globosum in Biocontrol of Pythium ultimum, a Causal Agent of DampingOff. Phytopathology 82 (2): 131-135.
Domsch K. H., Gams W. and Anderson T. H., 1980. Compendium of soil fungi, Volume 1. Academic Press, London, $859 \mathrm{p}$.

Ebbels D. L. and Allen D. J., 1979. A supplementary and annotated list of plant diseases, pathogens and associated fungi in Tanzania. Phytopathol. Pap. 22, 1-89.

Ellis M.B., 1971. Dematiaceous Hyphomycetes. Commonwealth Mycological Institute Kew, Surrey, England, $608 \mathrm{p}$.

Freeman S. and Katan T., 1997. Identification of Colletotrichum species responsible for anthracnose and root necrosis of strawberry in Israel. Phytopathology 87 (5): 516-521.

Gabriolotto C., Monchiero M., Gre M. L., Spadaro D. and Gullino M. L., 2009. Effectiveness of control strategies against Botrytis cinerea in vineyard and evaluation of the residual fungicide concentrations. Journal of Environmental Science and Health, Part B, 44 (4): 389-396.

Gerlagh M., Amsing J. J., Molhoek W. M. L., Boskervan Zessen A. I., Lombaers-van der Plas C. H. and Köhl. J., 2001. The effect of treatment with Ulocladium atrum on Botrytis cinerea-attack of Geranium (Pelargonium zonale) stock plants and cuttings. European Journal of Plant Pathology 107 (4): 377-386.

Gilman C. J., 1957. A manual of soil fungi, Second Edition. The lowa State College Press-Ames, lowa, U.S.A., $452 \mathrm{p}$.

Gohari A. M., Sedaghat N., Javan-Nikkhah M. and Saberi-Riseh R., 2007. Mycoflora of Wheat Grains in the Main Production Area in Kerman Province, Iran. International Journal of Agriculture and Biology 9 (4): 635-637.

González-Pérez E., Yáñez-Morales M. J., OrtegaEscobar H. M. and Velázquez-Mendoza J., 2008. First report of Acremonium strictum and Gliocladium roseum causing basal stem and corm rot of Gladiolus grandiflorus in Mexico. Journal of Plant Pathology 90 (3): 586.

Guillemond B. O. and Chamberland H., 2006. Tissue invasion and alteration in eggplant infected with Verticillium dahliae: A light and transmission electron microscopy study. Phytoprotection 87 (1): 29-42.

Gupta S., Dubey A. and Singh T., 2011. Fusarium semitectum as a dominant seed-borne pathogen in Dalbergia sissoo Roxb., its 
location in seed and its phytopathological effects. Indian Journal of Fundamental and Applied Life Sciences 1 (1): 5-10.

Hausbeck M. K. and Moorman G. W., 1996. Managing Botrytis in greenhouse -grown flower crop. Plant Disease 80 (11): 1212-1217.

Hernandez-Perez P. and du Toit L. J., 2006. Seedborne Cladosporium variabile and Stemphylium botryosum in spinach. Plant Disease 90 (2): 137-145.

Howard C. D., Maas J. L., Chandler C. K. and Albregts E. E., 1992. Anthracnose of strawberry caused by Colletotrichum complex in Florida, Plant Disease 76 (10): 976-981.

Huang H. C. and Erickson R. S., 2007. Biological control of Sclerotinia stem rot of canola using Ulocladium atrum. Plant Pathology Bulletin 16: 55-59.

Hubballi M., Nakkeeran S., RaguchanderT., Anand T. and Samiyappan R., 2010. Effect of environmental conditions on growth of Alternaria alternata causing leaf blight of noni. World Journal of Agricultural Sciences 6 (2): 171-177.

Hussein M. A. M., Hassan M. H. A., Allam A. D. A. and Abo-Elyousr K. A. M., 2007. Management of Stemphylium Blight of Onion by using Biological Agents and Resistance Inducers. Egyptian Journal of Phytopathology 35 (1): 4960.

Hyeon N. M., Park M. S., Kim H. G. and Yoo S. J., 2009. Biological control of strawberry Fusarium wilt caused by Fusarium oxysporum f. sp. fragariae using Bacillus velezensis BS87 and RK1 formulation. Journal of Microbiology Biotechnology 19 (5): 520-524.

Irwin J. A. G., 1984. Etiology of a new Stemphylium incited leaf disease Alfalfa in Australia. Plant Disease 68 (6): 531-532.

Jabnoun-Khiareddine H., Daami-Remadi M., Ayed F. and El Mahjoub M., 2007. Incidence and distribution of Verticillium dahliae races infecting tomato in Tunisia. Tunisian Journal of Plant Protection 2 (2): 63-70.

Jabnoun-Khiareddine $H_{\text {. }}$, Daami-Remadi M., Barbara D. J. and El Mahjoub M., 2010. Morphological variability within and among Verticillium species collected in Tunisia. Tunisian Journal of Plant Protection 5 (1): 19-38.
Jiskani M. M., Pathan M. A., Wagan K. H., Imran M. and Abro H., 2007. Studies on the control of tomato damping-off disease caused by Rhizoctonia solani Kuhn. Pakistan Journal of Botany 39 (7): 2749-2754.

Kim J. T., Park I. H., Lee H. B., Hahm Y. I. and Yu S. H., 2001. Identification of Verticillium dahliae and $V$. albo-atrum causing wilt of tomato in Korea. The Plant Pathology journal (The Korean Society of Plant Pathology) 17 (4): 222-226.

Köhl J., Gerlagh M., De Haas B. H. and Krijger M. C., 1998. Biological control of Botrytis cinerea in cyclamen with Ulocladium atrum and Gliocladium roseum under commercial growing conditions. Phytopathology 88 (6): 568-575.

Köhl J., Malhoek W. M. I., van der Plas C. H. and Fokkema N. J., 1995. Effect of Ulocladium atrum and other antagonists on sporulation of Botrytis cinerea on dead lily leaves exposed to field conditions. Phytopathology 85 (4) : 393401.

Koike S. T., Henderson D. M. and Butler E. E., 2001. Leaf spot disease of spinach in California caused by Stemphylium botryosum. Plant Disease 85 (2): 126-130.

Lagziri M. and El Amrani A., 2009. Effect of a microbialbased acaricidal product on spotted and predatory spidermites. African Crop Sciences Journal 17 (3): 111-123.

Lamindia J. A., 2002. Seasonal populations of Pratylenchus penetrans and Meloidogyne hapla in strawberry roots. Journal of Nematology 34 (4): 409-413.

Lansari A., 1985. Chemical weed control and effect of herbicides in strawberry (cv. Tioga) plantation in Morocco. Revue Horticole 257: 27-30.

Li L. and Yang H., 2011. First report of strawberry necrotic virus in China. Plant Disease 95 (9) : 1198.

Li S. and Hartman G. L., 2000. First Report of Stachybotrys chartarum causing soybean root rot. Plant Disease 84 (1) : 100.

Lockhart C. L., MacNab A. A. and Bolwyn B., 1969. A systemic fungicide for control of Verticillium wilt in strawberries. Canadian Plant Disease Survey (49) 2: 46-48. 
Lowings P. H., 1956. The Fungal Contamination of Kentish Strawberry Fruits in 1955. Applied Microbiology 4 (2): 84-88

Maas J. L., 1984. Compendium of strawberry diseases. American Phytopathological Society, St Paul, Minnesota, USA, 138 pp.

MacKenzie S. J., Xiao C. L., Mertely J. C., Chandler C. K., Martin F. G. and Legard D. F., 2003. Uniformity of strawberry yield and incidence of Botrytis fruit rot in an annual production system. Plant Disease 87 (8): 991-998.

Maouni A. Lamarti A. Aidoun A. Khaddor M. and Badoc A., 2007. Effect of benzimidazole fungicides and calcium chloride on Alternaria alternata and Penicillium expansum rot during storage of pears. African Journal of Biotechnology 6 (11): 1289-1292.

Martin R. R., Tzanetakis I. E., Barnes J. E. and Elmhirst J. F., 2004. First report of strawberry latent ring spot virus in strawberry in United States and Canada. Plant Disease 88 (5): 575.

Masunaka A., Ohtani K., Peever T. L., Timmer L. W., Tsuge T., Yamamoto M., Yamamoto $H$. and Akimitsu K., 2005. An isolate of Alternaria alternata that is pathogenic to both tangerines and rough lemon and produces two hostselective toxins, ACT- and ACR-toxins. Phytopathology 95 (3) : 241-247.

Mdarhri M., 2005. Isolement et identification de l'agent responsable de la maladie bactérienne des tâches angulaires du fraisier (Xanthomonas fragariae). Thèse $3^{\text {ème }}$ Cycle Agronomie, Option Phytiatrie, Complexe Horticole, Institut Agronomique et Vétérinaire Hassan II, Agadir (Maroc), $38 \mathrm{pp}$.

Meddah N., Ouazzani Touhami A. and Douira A., 2010. Mycoflore associée au bananier (Musa accuminata L.), variété Grande naine, cultivé sous serre dans la région du Gharb (Maroc). Bulletin de l'Institut Scientifique, Rabat, section Sciences de la Vie 32 (1): 1-11.

Meddah N., Ouazzani Touhami A., Benkirane R. and Douira A., 2006. Caractérisation de la mycoflore pathogène d'Hibiscus rosa-sinensis L. et d'Acalypha wilkesiana J. Mueller de la ville de Kénitra (Maroc). Bulletin de I'Institut Scientifique, Rabat, section Sciences de la Vie $28: 7-11$.

Mercier J., Makhlouf J. and Martin R. A., 1991. Fusarium avenaceum, a pathogen of stored broccoli. Canadian Plant Disease Survey 71 (2): 161-162.

Moline H. E. and Kuti J. O., 1984. Comparative studies of two Mucor species causing postharvest decay of tomato and their control. Plant Disease 68 (6): 524-526.

Moody A. R. and Gindrat D., 1977. Biological control of cucumber black root rot by Gliocladium roseum. Phytopathology 67 (9) : 1159-1162.

Mouria B., 2009. Contribution à la lutte biologique contre la pourriture grise et la verticilliose de la tomate cultivée sous serre par utilisation du compost et les Trichoderma spp. seul ou en combinaison. Thèse de Doctorat National. Université Ibn Tofail. Faculté des Sciences, Kénitra, Maroc, $295 \mathrm{p}$.

Mwakutuya E., 2006. Epidemiology of Stemphylium blight on lentil (Lens Culinaris) in Saskatchewan. A Thesis Submitted to the College of Graduate Studies and Research . Department of Plant Sciences. University of Saskatchewan. Saskatoon, 90 pp.

Nicolov P., 2006. Study on the fauna of the strawberry. $V$. Survey of the strawberry fauna. Ecology and Future - Bulgarian Journal of Ecological Science 5 (2): 38-40.

Norse D., 1974. Plant diseases in Barbados. Phytopathol. Pap. 18, 1-38.

O'Neill T. M., Shtienberg D. and Elad Y., 1997. Effect of Some Host and Microclimate Factors on Infection of Tomato Stems by Botrytis cinerea. Plant Disease 81 (1): 36-40.

Oleskevich C., Shamoun S.F., Vesonder R. F. and Punja Z. K., 1998. Evaluation of Fusarium avenaceum and other fungi for potential as biological control agents of invasive Rubus species in British Columbia. Canadian Journal of Plant Pathology 20 (1): 12-18.

Paulus A. O., 1990. Fungal diseases of strawberry. Journal HortScience 25 (8) : 885-889.

Ponchet A., 1966. Etude des contaminations mycopéricarpiques du caryopse du blé. Crop Research (Hisar) 7 (3): 554-460.

Pornsuriya C., Lin F. C., Kanokmedhakul S. and Soytong K., 2008. New record of Chaetomium species isolated from soil under pineapple plantation in Thailand. International Journal of Agricultural Technology 4 (2): 91-103.

Pryor B. M. and Michailides T. J., 2002. Morphological, pathogenic, and molecular characterization of 
Alternaria isolates associated with Alternaria late blight of pistachio. Phytopathology 92 (4): 406-416.

Rabeendran N, Jones E. E. and Stewart A., 1998. Isolation and in vitro screening of soil fungi for biological control of Sclerotinia sclerotiorum Microbial Control of Plant Pathogens, Proceedings of the New Zealand Plant Protection Conference 51: 102-106.

Rajput N. A., Pathan M. A., Jiskani M. M., Rajput A. Q. and Arain R. R., 2008. Pathogenicity and host range of Fusarium Solani (Mart.) Sacc. causing dieback of Shisham (Dalbergia Sissoo Roxb.). Pakistan Journal of Botany 40 (6): 2631-2639.

Rapilly F., 1968. Les techniques de mycologie en pathologie végétale. Annales des Epiphyties, Institut National de la Recherche Agronomique Paris, V19 no. Hors-série, $103 \mathrm{p}$.

Rodrigues A. A. C. and Menezes M., 2006. Identification and pathogenic characterization of endophytic Fusarium species from Cowpea seeds. Anais da Academia Pernambucana de Ciência Agronômica, Recife 3: 203-215.

Saber M. M., Sabet K. K., Moustafa-Mahmoud S. M. and Khafagi I. Y. S., 2003. Evaluation of biological products, antioxidants and salts for control of strawberry fruits rots. Egyptian Journal of Phytopathology 31 (1-2): 31-43.

Schmid A., Daniel C. and Weibel F., 2005. Effect of cultural methods on leaf spot (Mycosphaerella fragariae) and gray mold (Botrytis cinerea) damage in strawberries. BioControl 50 (1): 179-194.

Seta S., Gonzalez M. and Lori G., 2004. First report of walnut canker caused by Fusarium incarnatum in Argentina. Plant Pathology 53: 248.

Shivas R.G., 1989. Fungal and bacterial diseases of plants in Western Australia. J. Roy. Soc. W. Australia $72: 1-62$.

Sibounnavong P., Soytong K., Divina C. C. and Kalaw S. P., 2009. In vitro biological activities of Emericella nidulans, a new fungal antagonist, against Fusarium oxysporum f. sp. lycopersici. International Journal of Agricultural Technology 5 (1): 75-84.

Smith B. J. and Black L. L., 1990. Morphological, cultural, and pathogenic variation among Colletotrichum species isolated from strawberry. Plant Disease 74 (1): 69-76.
Souza-Motta C. M. D., Cavalcanti M. A. Q., Fernandes M. J. S., Lima D. M. M., Nascimento J. P. and Laranjeira D., 2003. Identification and characterization of filamentous fungi isolated from the sunflower (Helianthus annus L.) rhizosphere according to their capacity to hydrolyse inulin. Brazilian Journal of Microbiology 34 (3): 273-280.

Steffek R., Spornberger A. and Altenburger J., 2006. Detection of microsclerotia of Verticillium dahliae in soil samples and Prospects to Reduce the Inoculum potential of the fungus in the soil. Agriculturae Conspectus Scientificus 71 (4): 145-148.

Sundravadana S., Alice D., Kuttalam S. and Samiyappan R. 2007. Azoxystrobin activity on Rhizoctonia solani and its efficacy against rice sheath blight. Tunisian Journal of Plant Protection 2: 79-84.

Talubnak C. and Soytong K., 2010. Biological control of Vanilla anthracnose using Emericella nidulans. International Journal of Agricultural Technology 6 (1): 47-55.

Tanaka M. A. D. S., Ito M. F. and Passos F. A., 1995. Pathogenicity of Rhizoctonia solani to strawberry. Bragantia 54 (2): 319-324.

Tarr S., 1962. Diseases of Sorghum, Sudan Grass and Broom Corn. CAB, the Commonwealth Mycological Institute, Kew, $380 \mathrm{p}$.

Terakami S., Adachi Y., Iketani H., Sato Y., Sawamura Y., Takada N., Nishitani C. Y. and Amamoto T., 2007. Genetic mapping of genes for susceptibility to black spot disease in Japanese pears. Genome 50 (8): 735-741.

Vallad G. E., Bhat R. G., Koike S. T., Ryder E. J. and Subbarao K. V., 2005. Weedborne reservoirs and seed transmission of Verticillium dahliae in lettuce. Plant Disease 89 (3): 317-324.

Wada H., Cavanni P., Bugiani R., Kodama M., Otani H., and Kohmoto R., 1996. Occurrence of the strawberry of Alternaria alternata in Italy. Plant Disease 80 (4) : 372-374.

Walali Loudyi D. E. M. and Skiredj A., 2003. Fiches techniques: Le cognassier, le néflier, le fraisier, le pêcher et le figuier de barbarie. Transfert de Technologie en Agriculture MADER/DERD_PNTTA (Ed.), Ministère de I'Agriculture et du Développement Rural, Bulletin Mensuel d'information et de liaison du PNTTA. $n^{\circ} 110$ (Arboriculture) : 4 pp. 
Wallbridge A., 1981. Fungi associated with crown-rot disease of boxed bananas from the windward islands during a two-year survey. Trans. Brit. Mycol. Soc., 77, 567-577.

Williams T.H. and Liu, P.S.W., 1976. A host list of plant diseases in Sabah, Malaysia. Phytopathol. Pap., 19, 1-67.

Xue A. G. and Davidson C. G., 1995. Occurrence of anthracnose fruit rot caused by Colletotrichum acutatum on day-neutral strawberries in Manitoba. Canadian Plant Disease Survey 75 (2) : 185-190.

Xue A. G., Ho K. M., Butler G., Vigier B. J. and Babcock C., 2006. Pathogenicity of Fusarium species causing head blight in barley. Phytoprotection 87 (2): 55-61.
Yu H. and Sutton J. C., 1998. Effects of inoculums density, wetness duration, and temperature on control of Botrytis cinerea by Gliocladium roseum in raspberry. Canadian Journal of Plant pathology 20 (3): 243- 252.

Zahdali G., 2003. Evaluation des niveaux de résistance de Tetranychus urticae Koch à différents acaricides d'usage fréquents sur fraisier à Loukkos. Mémoire $3^{\text {ème }}$ Cycle Institut Agronomique et Vétérinaire Hassan II, Rabat, $125 \mathrm{pp}$.

Zhao G. H., Li D. W., Jiang J. H. and Peng J., 2010. First report of Stachybotrys chartarum causing leaf blight of Tillandsia tenuifolia in China. Plant Disease 94 (9): 1166. 